\title{
To Review or Not to Review? Limited Strategic Thinking at the Movie Box Office ${ }^{1}$
}

\author{
Alexander L. Brown \\ Texas A\&M University \\ Colin F. Camerer \\ California Institute of Technology \\ Dan Lovallo \\ The University of Sydney
}

\footnotetext{
${ }^{1}$ Thanks to audiences at Caltech, especially David Grether, Stuart McDonald, Tom Palfrey, Charles Plott, Robert Sherman, and Leeat Yariv. Thanks also to audiences at Chicago GSB, Berkeley, Yale Graduate Student Conference on Behavioral Science, 2007 North American ESA, SJDM and SEA. Thanks to Dan Knoepfle for proofreading, Sera Linardi for a suggestion that lead to an 8-fold improvement in $\mathrm{CH}$ runtimes, Esther Hwang, Carmina Clarke, Ferdinand Dubin, and especially Jonathan Garrity for help with data collection. Direct correspondence to Alexander L. Brown at abrown@econmail.tamu.edu.
} 


\begin{abstract}
Film distributors occasionally withhold movies from critics before their release. Cold openings provide a natural field setting to test models of limited strategic thinking. In a set of 856 widely released movies, cold opening produces a significant $15 \%$ increase in domestic box office revenue (though not in foreign markets and DVD sales), consistent with the hypothesis that some moviegoers do not infer low quality from cold opening. Structural parameter estimates indicate 1-2 steps of strategic thinking by moviegoers (comparable to experimental estimates). However, movie studios appear to think moviegoers are sophisticated since only $7 \%$ of movies are opened cold.
\end{abstract}




\section{Introduction}

The hypothesis that economic agents can correctly infer what other agents know from their actions is a central principle in analysis of games with information asymmetry. A contrasting view is that strategic thinking can be limited by cognitive constraints. In this view, players with private information can fool some of the people, some of the time, in contrast to the standard equilibrium assumption that nobody is fooled. ${ }^{1}$

One class of models of limited strategic thinking assumes there is a 'cognitive hierarchy' $(\mathrm{CH})$ of levels of steps of thinking. Low-level players do not think strategically, and higher-level players anticipate the behavior of lower-level players correctly. These models have been used to explain experimental data from a wide variety of normal-form games. ${ }^{2}$ The many examples studied include both games in which behavior deviates systematically from equilibrium and others in which behavior is surprisingly close to equilibrium even without learning or other equilibrating forces (e.g., Östling et al. 2007). The only applications of these theories to games with private information so far are analyses of auctions. ${ }^{3}$ Another class of models, which apply on to private-information games, are models of 'cursed equilibrium.' In these models agents ignore the possible link between information and actions of other players to some degree (Eyster and Rabin, 2005).

Models of limited strategic thinking are particularly useful if the same basic principles can apply to many different games, to field data, and to experimental data. This paper explores the generality of these approaches through the first empirical comparison of the $\mathrm{CH}$ and cursed equi-

\footnotetext{
${ }^{1}$ See Crawford (2003).

${ }^{2}$ See Nagel (1995), Stahl and Wilson (1995), Camerer et al. (2004), Crawford and Iriberri (2007a).

${ }^{3}$ See Crawford and Iriberri (2007b) and Wang (2006).
} 
librium model in private-information games using field data. ${ }^{4}$ (Full rationality is also part of the comparison since it is a limiting case of both the $\mathrm{CH}$ and cursed models.)

The setting is Hollywood. Movie distributors generally show movies to critics well in advance of the release (so that critics' reviews can be published or posted before the movie is shown, and can be quoted in newspaper ads). However, movies are sometimes deliberately made unavailable until after the initial release, a practice sometimes called "cold opening." If moviegoers believe that distributors know their movie's quality (and if some other simplifying assumptions hold), we show in the next section that rational moviegoers should infer that cold opened movies are below average in quality. Anticipating this inference, distributors should only cold open the very worst movies. However, this conclusion requires many steps of iterated reasoning (as well as many simplifying assumptions). So it is an empirical question whether the equilibrium prediction holds. If it does not hold perfectly, it is also an empirical question, whether neoclassical explanations can explain the data or models of limited strategic thinking designed to explain experimental data can fit the distributors' cold opening decisions and the box office response.

This setting is one example of a more general class of disclosure games in which a seller who knows something about a product's quality can choose whether to disclose a signal of its quality or not (see Verrecchia (2001, section 3) and Fishman and Hagerty (2003) for surveys). For instance, a car salesman can signal a vehicle's quality by adding a warranty (Grossman, 1981). A

\footnotetext{
${ }^{4}$ Two unpublished studies using field data and cognitive hierarchy approaches are Östling et al., (2007) using Swedish lottery choices and experimental analogues, and Goldfarb and Yang (2007) using estimation of firm adoption of 56K modems. The Östling et al. study compares QRE and cognitive hierarchy approaches but Goldfarb and Yang do not compare to QRE, and neither paper estimates the cursed equilibrium model as we do since both are modeled as complete information games.
} 
regulated firm can selectively report information about its industry to regulators (Milgrom, 1981). Restaurants can voluntarily post health department ratings even if they aren't required to by law (Jin and Leslie, 2003). HMOs can choose whether to voluntarily disclose quality by submitting to independent accreditation (Jin, 2005). A hedge fund can selectively report past earnings (Malkiel and Saha, 2005). Online daters can decide whether to post a picture or not (Hitsch et al., 2006). Sellers in online auctions can selectively disclose shipping charges (Brown et al., 2007). Colleges can incentivize good (or bad) students to disclose (or not disclose) their SAT scores to US News and World Report (Conlin et al., 2008). In politics and law, the analogous situation is when one can choose to disclose the answer a direct question, or can avoid answering the question (e.g.," pleading the fifth" in legal settings).

For regulators, what consumers infer from non-disclosure is important for deciding whether disclosure should be voluntary or mandatory. If consumers do not infer that nondisclosure is bad news about quality, an economic argument can be made for mandatory disclosure under some conditions. We return to this topic briefly in the conclusion.

\subsection{Basic ideas}

A fully rational analysis, due originally to Grossman (1981) and Milgrom (1981), implies that cold opening should not be profitable if some simple assumptions are met. The argument can be illustrated numerically with a highly simplified example. Suppose movie quality is uniformly distributed from 0 to 100, moviegoers and distributors agree on quality, and firm profits increase in quality. If distributors cold open all movies with quality below a cutoff 50, moviegoers with rational expectations will infer that the expected quality of a cold opened movie is 25 . But then it 
would pay to screen all movies with qualities between 26 and 100, and only cold open movies with qualities 25 or below. Generally, if the distributors do not screen movies with qualities below $q^{*}$, the consumers' conditional expectation if a movie if unscreened is $q^{*} / 2$, so it pays to screen movies with qualities $q \in\left(q^{*} / 2,100\right]$ rather than quality below $q^{*}$. The logical conclusion of iterating this reasoning is that only the worst movies (quality 0 ) are unscreened. This conclusion is sometimes called "unravelling."

Whether there is complete unraveling, in theory, is sensitive to some of the simplifying assumptions (see Milgrom 2008). If disclosure is costly (Viscusi, 1978; Jovanovic, 1982), sellers will only reveal information down to a certain threshold of low quality. ${ }^{5}$ In other cases, sellers may know the quality of their own product with some probability (Dye, 1985; Jung and Kwon, 1988; Shin, 1994; Dye and Sridhar, 1995; Shin, 2003), or can only learn the quality at a cost (Matthews and Postlewaite, 1985; Farrell, 1986; Shavell, 1994). Fishman and Hagerty (2003) assume a portion of consumers are unable to interpret revealed information, but this does not necessarily lead to limited disclosure. ${ }^{6}$

These conditions which may prevent unravelling do not characterize the movie business particularly well. The median production budget in our sample is $\$ 35$ million, the marketing budgets are often comparable in scale (50-100\% of the production budget), but the costs of arranging screenings for critics (or now, sending DVDs) is on the scale of thousands of dollars. Furthermore, sellers usually know a lot about quality—as judged by likely moviegoers—because movies are almost al-

\footnotetext{
${ }^{5}$ Intuitively, even if low-quality movies below the threshold are pooled in with inferior movies, if disclosure is costly then the penalty from being in the same pool is tolerable if it is below the cost of disclosing.

${ }^{6}$ They find three equilibria—one in which quality is always revealed, one in which it is never revealed, and one in which high quality is revealed and low quality is not.
} 
ways screened for test audiences, and learning about quality perceptions from these tests is not costly. Therefore, we proceed with the maintained hypothesis that complete unravelling should occur in theory, if distributors and consumers are perfectly rational.

What do models of limited strategic thinking predict? The cognitive hierarchy models proceed through the steps of strategic thinking in the rational unravelling argument, except that they assume that some fraction of moviegoers end their inference process after a small number of steps. For example, a level-0 moviegoer thinks that cold opening decisions are random (they convey no information about quality) and hence infers that the quality of a cold-opened movie is average. A level-1 distributor anticipates that moviegoers think this way and therefore opens all belowaverage movies cold, and shows all above-average movies to critics. Higher-level thinkers iterate this process. Observed behavior will then be an average of the predicted behaviors at each of these levels weighted by the fraction of moviegoers and distributors who do various numbers of steps of thinking (More details of this model are given in section 4).

The model of cursed equilibrium is similar. It assumes that a fraction of moviegoers form the correct conditional expectation of quality given a cold opening (i.e, those moviegoers act as if they know precisely how distributors map quality into the decision about whether to cold open). The remaining fraction believe_-mistakenly — that cold opened movies are random in quality, neglecting the link between distributors' information about quality and their cold opening choice. Note that full rationality is a special case of both models.

Industry executives and analysts who describe the cold opening decision often imply that limited moviegoer rationality justifies a cold opening, because they say that a bad review can hurt more than a non-review does. ${ }^{7}$ For example, Greg Basser, CEO of Village Roadshow Entertain-

\footnotetext{
${ }^{7}$ Another explanation for cold opening is that the movie was not ready to be released to critics, or that the movie
} 
ment Group, told us, "If you screen [a bad movie] for critics all they can do is say something which may prevent someone from going to the movie." As Dennis Rice, the former Disney publicity chief put it, "If we think screenings for the press will help open the movie, we'll do it. If we don't think it'll help... then it may make sense not to screen the movie," (Germain, 2006). Litwak (1986) notes

"As a courtesy, and to ensure that reviews are ready by the time a film is released, distributors arrange advance screenings for critics. However, if negative reviews are expected, the distributor may decide not to screen a picture, hoping to delay the bad news. (p. 241)"

The data we describe next show that $7 \%$ of the movies in our sample are opened cold (though that fraction has increased sharply in recent years). Regressions show that cold opening appears to generate a box office premium (compared to similar-quality movies that are pre-reviewed, and including many other controls), which is consistent with the hypothesis that some consumers are overestimating quality of movies that are opened cold. We apply several mechanical explanations, but none can plausibly explain the findings.

We then fit the two parametric models of limited strategic thinking (described above) to both moviegoer and distributor decisions. The models parameterize the degree of strategic thinking by one parameter, so we can characterize the degree of limited rationality numerically (and also contained a surprise that reviewers might spoil (e.g., "Sixth Sense", "Cloverfield", "Blair Witch Project"). In the first case, it is very rare that a film uses this explanation for a cold opening, to our knowledge only one movie ("Doogal”) in our dataset has made this claim (Germain, 2006). On the second item, "Sixth Sense", "Cloverfield", and "Blair Witch" were all released to critics. None of the 59 movies that were cold opened in the data sample featured such intense plot twists. Normally, such plot twists are an example of high-quality writing, something which the typical cold-opened movie does not feature. See next section for a description of the quality of cold opened movies. 
compare the results to experimental estimates). The best-fitting $\mathrm{CH}$ model parameters suggest that moviegoers are doing an average of 1.12 steps of thinking, which is lower but roughly comparable to estimates from many experiments (1-2 steps). However, given the box office premium, distributors should be opening many more movies cold. Within the restrictive structure of the $\mathrm{CH}$ model, the only possible explanation is that distributors think moviegoers are more sophisticated than they really are, so the distributors' estimated average number of perceived thinking steps is around 8. The mismatch between the degree of strategic thinking of moviegoers and distributors is not typically observed in experimental data. However, keep in mind that experiments rarely use mixtures of populations which are more and less strategically sophisticated, so it is perhaps not surprising that the estimate of distributor strategic thinking is very high, and is much higher than the moviegoer estimates.

The paper is organized as follows: Section 2 discusses the data we use on quality ratings, box-office returns, and control variables, and presents some regression results on the existence and robustness of a box-office premium for movies that are opened cold. Section 3 describes the $\mathrm{CH}$ and cursed equilibrium models (including "quantal response equilibrium" (QRE), which is a special case of the cursed model), and section 4 estimates parameters of those models based on distributors' decisions and the box office revenue. Section 5 concludes and discusses related empirical results on disclosure effects, which are generally consistent with ours. 


\section{Data}

The data set is all 890 movies widely released ${ }^{8}$ in the U.S. in their first weekend, over the $6 \frac{1}{2}$ year period from January 1, 2000 to June 30, 2006. ${ }^{9}$

Critic and moviegoer ratings are both used to measure quality. Metacritic.com ratings are used to measure critic ratings. Metacritic.com normalizes and averages ratings from over 30 movie critics from newspapers, magazines, and websites. The metacritic rating is available for all noncold-opened movies on the day they are released and is available on Monday for cold opened movies. We assume their ratings are generally exogenous from box office revenue measures. ${ }^{10}$

A natural question to ask is whether metacritic ratings accurately express the quality of movies as perceived by moviegoers and revealed by demand. Our analysis indicates that they do for example, our regressions (discussed later) show a very sharp correlation between critic ratings and box office revenues. This result is also found in other studies of critic influence (Eliashberg and Shugan, 1997; Reinstein and Snyder, 2005).

We also examine the aggregated user ratings on imdb.com, which is the largest internet site for user movie reviews. There is a high correlation (.76) between metacritic scores and imdb user reviews (see Figure 1). The high correlation between critic (metacritic) and the moviegoer (IMDB

\footnotetext{
${ }^{8}$ Attention is restricted to movies initially released in over 300 theaters. Movies in more limited release have much less box office impact (they are usually art house movies that use a platform strategy of starting on a few screens, then expanding). It is also likely that information about quality leaks out more rapidly for these movies if they later go into wide release, even when they are initially opened cold.

${ }^{9}$ Movies before 2000 are excluded because Metacritic.com's records did not cover every movie from before 2000.

${ }^{10}$ Ratings such as the imdb.com user rating are determined by the people who see the movie and who give reviews afterwards. We treat that variable as a measure of popularity, but consider it endogenous to box office.
} 


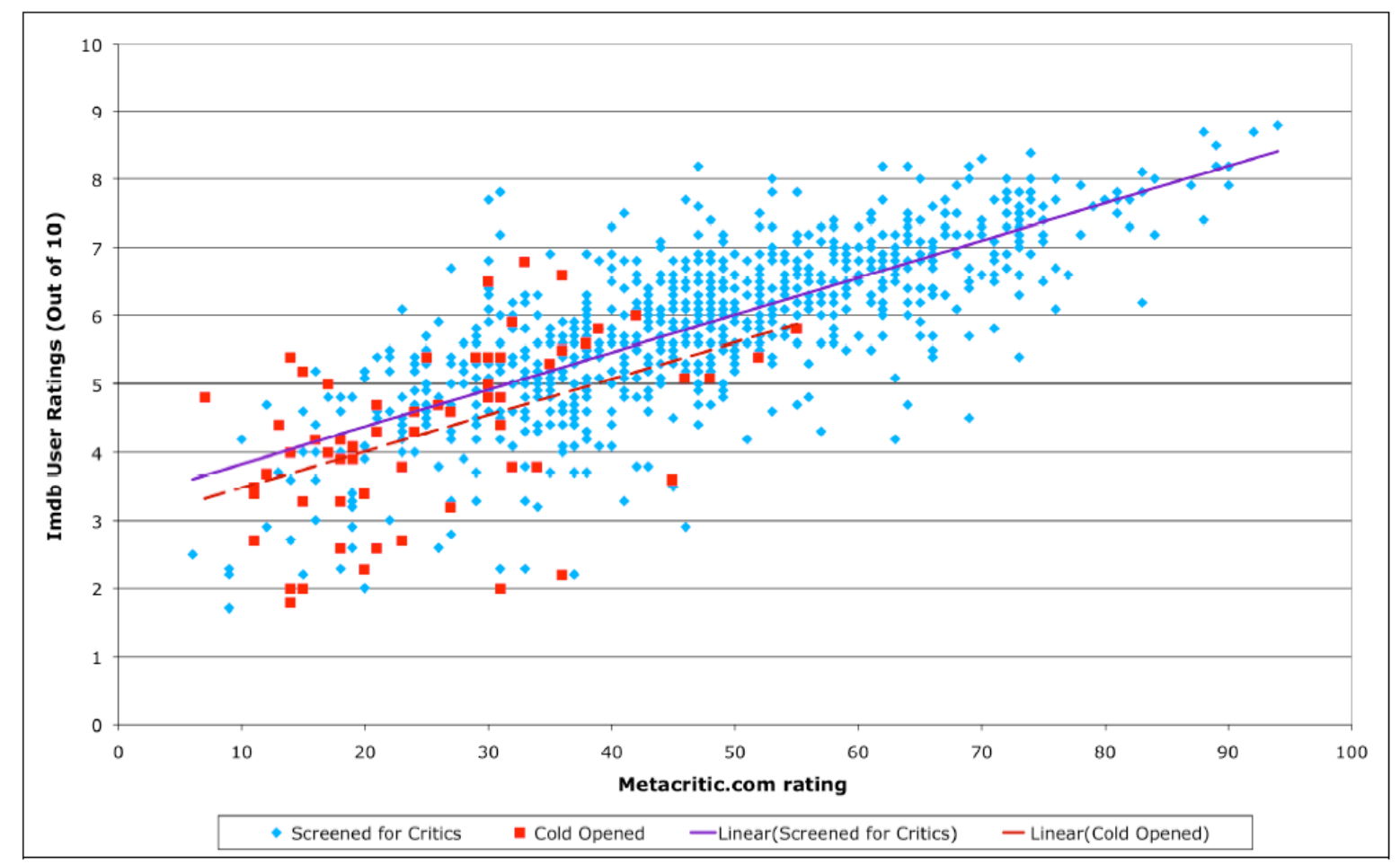

Figure 1: Scatter plot of metacritic.com quality ratings and imdb user ratings

ratings) holds across movie to genres (see Table 4 below). Metacritic scores therefore correlate with two clear indicators of movie popularity (imdb and box office). ${ }^{11}$

The squares in Figure 1 represent the cold opened movies in our sample. No cold opened movie has a metacritic rating higher than 55 , and the average rating for those movies (the total sample

${ }^{11}$ We are assuming that critic reviews influence moviegoers. Alternatively, critics might correlate with overall popularity (as our previous evidence suggests), but moviegoers ignore them so they have predictive, but not influencing power. Survey evidence suggests one third of moviegoers use critical reviews to make decisions (Simmons, 1994). But the empirical work of Eliashberg and Shugan (1997) finds it impossible to reach a definitive conclusion on this issue, and Reinstein and Snyder (2005) find evidence that critic ratings only matter for specific genres. However, the latter study only examines the effect of two critics (i.e., Siskel and Ebert) delaying their review. A cold opening delays all reviews and thus might have a greater effect across genres. Because this evidence is somewhat inconclusive, we will use several different tests to check our hypothesis that it is indeed the cold opening increasing box office and thus the critic reviews (or lack thereof) influencing moviegoers. 


\begin{tabular}{|l|r|r|r|}
\hline variable $\backslash$ regression & mean & median & standard dev \\
\hline cold & 0.070 & 0.000 & 0.255 \\
log total box office revenue (logcubo) & 3.443 & 3.510 & 1.092 \\
log 1st weekend box office revenue (logwkd) & 2.354 & 2.390 & 0.942 \\
metacritic rating (crit) & 45.793 & 46.000 & 16.813 \\
theaters opened (in thousands) (thtr) & 2.435 & 2.550 & 0.787 \\
production budget (in millions) (bud) & 42.299 & 33.360 & 33.484 \\
average competitor budget (in millions) (comp) & 44.127 & 36.020 & 31.080 \\
average log star ranking (star) & 4.645 & 4.533 & 1.692 \\
summer open (1=Jun, Jul, Aug) (sum) & 0.245 & 0.000 & 0.430 \\
sequel or adaptation (1=yes) (sq/adpt) & 0.389 & 0.000 & 0.488 \\
opening days bef fri (1=Thurs, etc.) (beffri) & 0.224 & 0.000 & 0.658 \\
opening wkd length (days) (wkdlen) & 0.109 & 0.000 & 0.336 \\
early foreign open (days) (forbef) & 11.804 & 0.000 & 99.724 \\
action/ adventure (1) (act/adv) & 0.164 & 0.000 & 0.371 \\
animated (1) (ani) & 0.060 & 0.000 & 0.237 \\
comedy (1) (com) & 0.380 & 0.000 & 0.486 \\
documentary (1) (doc) & 0.006 & 0.000 & 0.075 \\
fantasy/scifi (1) (fant/sci) & 0.062 & 0.000 & 0.241 \\
supense/ horror (1) (susp/hor) & 0.157 & 0.000 & 0.364 \\
year of release (2003=0) (year) & -0.166 & 0.000 & 1.902 \\
PG (1) (pg) & 0.158 & 0.000 & 0.365 \\
PG-13 (1) (pg13) & 0.478 & 0.000 & 0.500 \\
R (1) (r) & 0.326 & 0.000 & 0.469 \\
\hline
\end{tabular}

Table 1: Summary statistics for variables ( $N=890$ except $N=856$ for production budget).

average is 48 ) is 25 .

Cold opening, box office revenues, movie genres and ratings, production budgets, and star power ratings are collected from various data sources (see Appendix A for more details). Table 1 provides summary statistics for all variables. All these variables were used in a regression model to test if movies that are cold opened have significantly greater opening weekend and total US box office.

Each movie, $j$, has a metacritic.com rating, $q_{j}$, a dummy variable for whether a movie was cold 
opened, $c_{j}$ (=1 if cold), and a vector $X_{j}$ of other variables. The regression model is

$$
\log y_{j}=a X_{j}+b q_{j}+d c_{j}+\epsilon_{j}
$$

where $y_{j}$ is logged opening weekend or total US box office for movie $j$ in 2003 dollars, standardized using the GDP deflator (www . bea.gov). Table 2 shows the regression results.

The point of this initial regression is not to estimate a full model with endogenous distributor decisions (that will be done in Sections 3 and 4). Instead, the regression is simply a way of determining whether there is a difference in the revenue between cold opened and screened movies. Under the standard equilibrium assumption that all quality information of cold opened movies is inferred by logical inference of moviegoers, we should see no difference in revenues, and the cold coefficient should be zero. ${ }^{12}$

The "cold" coefficient in the first row of Table 2 shows that cold opening a movie is positively correlated with the logarithm of opening weekend and total US box office (see Appendix B, Table A.1 for a similar result with opening day data). ${ }^{13}$ These coefficients suggest that cold opening a movie increases revenue about $15 \% .{ }^{14,} 15$ These effects persist when "lean" regressions are run with

\footnotetext{
${ }^{12}$ Alternatively, a switching regression model (similar to Borjas, 1987) for the choice to cold opened could be used to capture the cold opening premium and characterize the decision to cold open. We have instead chosen to describe the industry through a quantal response model (see Section 4)

${ }^{13}$ Note that this relationship is also found between cold opening and opening weekend and total US box office (no logarithm). So this relationship is not just a result of the functional form of the regression.

${ }^{14}$ For the average gross of a cold opened movie, $\$ 20$ million, this is roughly $\$ 3$ million of box office revenue.

${ }^{15}$ These results do not change using imdb.com user ratings instead of metacritic ratings (although the imdb regression may include some endogeneity influence of box office buzz on imdb ratings).
} 


\begin{tabular}{|c|c|c|c|c|}
\hline \multirow{2}{*}{$\begin{array}{c}\text { independent } \\
\text { variable }\end{array}$} & \multicolumn{4}{|c|}{ dependent variable } \\
\hline & logcubo & \begin{tabular}{l|l}
$\log c u b o$ \\
\end{tabular} & logwkd & logwkd \\
\hline cold & $\begin{array}{l}0.154 * * \\
(0.090)\end{array}$ & $\begin{array}{c}0.140 * * \\
(0.088)\end{array}$ & $\begin{array}{l}0.147 * * \\
(0.073)\end{array}$ & $\begin{array}{c}0.171^{* * * *} \\
(0.073)\end{array}$ \\
\hline crit & $\begin{array}{c}0.021 * * * \\
(0.001)\end{array}$ & $\begin{array}{c}0.020 * * * \\
(0.001)\end{array}$ & $\begin{array}{c}0.013 * * * \\
(0.001)\end{array}$ & $\begin{array}{c}0.013 * * * \\
(0.001)\end{array}$ \\
\hline thtr & $\begin{array}{c}0.864 * * * \\
(0.039)\end{array}$ & $\begin{array}{c}0.853 * * * \\
(0.035)\end{array}$ & $\begin{array}{c}0.848 * * * \\
(0.032)\end{array}$ & $\begin{array}{c}0.820 * * * \\
(0.029)\end{array}$ \\
\hline bud & $\begin{array}{c}0.003 * * * \\
(0.001)\end{array}$ & $\begin{array}{c}0.002 * * * \\
(0.001)\end{array}$ & $\begin{array}{c}0.002 * * * \\
(0.001)\end{array}$ & $\begin{array}{c}0.002 * * * \\
(0.001)\end{array}$ \\
\hline comp & $\begin{array}{c}0.022 * * * \\
(0.001)\end{array}$ & $\begin{array}{c}0.003 * * * \\
(0.001)\end{array}$ & $\begin{array}{l}0.001 * * \\
(0.001) \\
\end{array}$ & $\begin{array}{c}0.001 * * \\
(0.001)\end{array}$ \\
\hline star & $\begin{array}{c}-0.045^{* *} \\
(0.015)\end{array}$ & $\begin{array}{c}-0.054 * * * \\
(0.014)\end{array}$ & $\begin{array}{c}-0.029 * * \\
(0.013)\end{array}$ & $\begin{array}{c}-0.048 * * * \\
(0.011)\end{array}$ \\
\hline sum & $\begin{array}{c}0.052 \\
(0.050)\end{array}$ & - & $\begin{array}{c}0.028 \\
(0.041)\end{array}$ & - \\
\hline sq/adpt & $\begin{array}{c}0.124 * * * \\
(0.045)\end{array}$ & $\begin{array}{c}0.116 * * * \\
(0.045)\end{array}$ & $\begin{array}{c}0.119 * * * \\
(0.037)\end{array}$ & $\begin{array}{c}0.111 * * * \\
(0.037)\end{array}$ \\
\hline beffri & $\begin{array}{c}0.000 \\
(0.033)\end{array}$ & - & $\begin{array}{l}-0.048^{*} \\
(0.027)\end{array}$ & - \\
\hline wkdlen & $\begin{array}{l}0.129 * * \\
(0.063)\end{array}$ & - & $\begin{array}{c}0.175 * * * \\
(0.051)\end{array}$ & - \\
\hline forbef & $\begin{array}{c}0.000 \\
(0.000)\end{array}$ & - & $\begin{array}{c}0.000 \\
(0.000)\end{array}$ & - \\
\hline act/adv & $\begin{array}{c}-0.173 * * \\
(0.078)\end{array}$ & - & $\begin{array}{l}-0.052 \\
(0.063)\end{array}$ & - \\
\hline ani & $\begin{array}{c}-0.316^{* *} \\
(0.128)\end{array}$ & - & $\begin{array}{l}-0.145 \\
(0.105)\end{array}$ & - \\
\hline com & $\begin{array}{c}0.032 \\
(0.064)\end{array}$ & - & $\begin{array}{c}0.027 \\
(0.052)\end{array}$ & - \\
\hline doc & $\begin{array}{c}0.212 \\
(0.362)\end{array}$ & - & $\begin{array}{c}0.267 \\
(0.052)\end{array}$ & - \\
\hline fant/sci & $\begin{array}{l}-0.175^{*} \\
(0.103)\end{array}$ & - & $\begin{array}{c}0.039 \\
(0.084)\end{array}$ & - \\
\hline susp/hor & $\begin{array}{c}0.012 \\
(0.078)\end{array}$ & - & $\begin{array}{c}0.040 \\
(0.064)\end{array}$ & - \\
\hline year & $\begin{array}{c}-0.083 * * * \\
(0.011)\end{array}$ & $\begin{array}{c}-0.082 * * * \\
(0.011)\end{array}$ & $\begin{array}{c}-0.050 * * * \\
(0.009)\end{array}$ & $\begin{array}{c}-0.050 * * * \\
(0.009)\end{array}$ \\
\hline $\mathrm{pg}$ & $\begin{array}{c}-0.182 \\
(0.130)\end{array}$ & - & $\begin{array}{c}-0.034 \\
(0.106)\end{array}$ & - \\
\hline $\mathrm{pg} 13$ & $\begin{array}{l}-0.179 \\
(0.136)\end{array}$ & - & $\begin{array}{c}0.100 \\
(0.111)\end{array}$ & - \\
\hline $\mathrm{r}$ & $\begin{array}{l}-0.225 \\
(0.140)\end{array}$ & - & $\begin{array}{c}0.113 \\
(0.114)\end{array}$ & - \\
\hline const & $\begin{array}{l}0.506 * * \\
(0.209)\end{array}$ & $\begin{array}{c}0.433 * * * \\
(0.134)\end{array}$ & $\begin{array}{c}-0.493 * * * \\
(0.171)\end{array}$ & $\begin{array}{c}-0.188 * * * \\
(0.110)\end{array}$ \\
\hline $\begin{array}{l}\text { R-squared } \\
\mathrm{N} \\
\text { degrees of freedom }\end{array}$ & $\begin{array}{r}0.677 \\
856 \\
21\end{array}$ & $\begin{array}{r}0.675 \\
856 \\
8\end{array}$ & $\begin{array}{r}0.718 \\
856 \\
21\end{array}$ & $\begin{array}{r}0.707 \\
856 \\
8\end{array}$ \\
\hline
\end{tabular}

Table 2: Regressions of log box office revenues (in millions) 
only the most significant variables included (i.e., cold, metacritic, theaters, budget, competition, star ranking, sequel or adaptation dummy, and year of release). The lean regressions show a more significant effect for opening weekend, than the effect for total box office, presumably because critic reviews of cold opened movies are normally available by the Monday after the opening weekend and they influence toal box office. ${ }^{16}$ The coefficients also suggest that cold opening increases movie revenue by roughly the same amount as in the full regressions (14-17\%). ${ }^{17}$

The regression coefficients in Table 2 are generally sensible. Higher quality leads to higher box office-an increase in one metacritic point increases revenues by $2.1 \%$. An extra $\$ 10$ million in production budget is correlated with a $3 \%$ increase in revenues. The number of theaters opened, which often indicate expectations about movie revenues, have a very large effect. ${ }^{18}$ An increase of 1000 theaters increases revenue by $86 \%$. The averaged logged star power rankings have a negative

\footnotetext{
${ }^{16}$ It is somewhat surprising that the effect of a cold opening continues after the first weekend when critical reviews are available. Intuitively, the cold opening effect should occur during the first weekend and then dissipate rapidly as moviegoers learn the true quality of a cold opened movie. An alternative explanation is that moviegoers infer quality from the first weekend's revenue (see De Vany and Walls (1996) for a model with such dynamics). Then the perceived "effect" of a cold opening on post-first-weekend box office includes a secondary result from cold opening affecting the first weekend's box office (as in models of herd behavior or cascades). The data agree with this assessment; if we run a regression on logged box office revenues after the first weekend (see Table A.2), including logged first weekend with our other independent variables, then we find cold has an slightly negative effect $(-3 \%, p \approx 0.5 ;-10 \%, p<0.1$ (lean)) on post-opening-weekend revenue, and a opening weekend is correlated with post-opening-weekend revenue $(120 \%, p<0.01)$

${ }^{17}$ The p-values on all the cold opening coefficients are based upon one-tailed tests because the hypothesis is that cold opening either increases revenue or has no effect.

${ }^{18}$ Theaters may be a proxy for the omitted variable of advertising budget as well, which magnifies the theater variable effect.
} 
correlation (higher numbers indicate lower rankings and less revenue). Adaptations and sequels increase box office by roughly $13 \%$, a result which may explain the recent growth in the fraction of movies in this category.

\subsection{Alternative Explanations of the Cold Opening Premium}

The central premise of this paper is that limited strategic thinking causes moviegoers to overvalue the quality of cold opened movies that are of below average quality, which is one possible explanation for why cold opened movies have a higher relative box office to similar movies that were screened for critics. The previous section finds evidence for that higher box office, but there may be other reasons for the observed premium. This section explores such possibilities and reports evidence against most of these explanations.

One apparent alternative explanation is that not everyone knows whether movies have been cold opened (e.g., it may be costly to find out ${ }^{19}$ ). Consumers who do not know whether movies were reviewed or not could believe the cold-opened movies have average quality (because they don't know they were unreviewed) and would therefore go to those movies more often than if they made the correct strategic inference. ${ }^{20}$

However, missing information about cold openings in this way simply means that some moviegoers have missing information about all critic reviews. Missing information biases the regression coefficient on critic-rated quality toward zero, but does not bias revenues of cold-opened movies

\footnotetext{
${ }^{19}$ In the conventional sense, it is not actually "costly" to find out about cold openings. Daily newspapers cost $\$ 1$ or less; if there is no review on the day of opening (almost always Friday) then the movie is cold opened.

${ }^{20}$ This example is very similar to having a moviegoers' curse for all movies rather than just the cold opened ones. See section 4.1 for an explanation of the cursed equilibrium model and footnote 35 for more detail.
} 
upward. The reason is that missing information creates an upward bias for all low-quality movies (compared to full information), but does not create a differential effect for low-quality movies which were cold opened compared to low-quality movies which were not cold-opened. That is, uninformed moviegoers would overvalue all movies of below average quality, including those which were not opened cold, and would undervalue all movies of above average quality as well. Ignoring critic information should produce a general "below-average-quality" premium (compared to full information) but will not create a cold-opening premium per se.

Other explanations are therefore more plausible as conceivable explanations of a cold opening premium. It is possible that cold opened movies have some characteristic omitted from the Table 2 regressions that causes these movies to generate apparently greater box office (a classic omitted variable bias). In this case, our regressions are not capturing the effect of cold opening, but are capturing the effect of an omitted variable that is correlated with cold opening.

However, all the obvious measurable controls are already included in Table 2. (Appendix B, Table A.3 also shows all correlations and indicates that cold opening is not strongly correlated with any variable except quality.) Since all obvious measurable controls are included, the most likely omitted variable that could be correlated with the decision to cold open is spending on publicity and advertising. ${ }^{21}$ Omitting this variable would explain the cold opening premium if revenues increase with spending on advertising, and if advance screening and advertising are substitutes (i.e., if distributors spend more on ads to compensate for cold opening but ad spending is an omitted variable). In our data cold openings are associated with a $10 \%$ drop in advertising, however. ${ }^{22}$ Furthermore,

\footnotetext{
${ }^{21}$ Unfortunately, we found advertising budgets for only 445 of the 856 movies in our sample, and only 12 of the 59 cold openings.

${ }^{22}$ The result is only based on 12 cold openings and is not significant $(\mathrm{p} \approx 0.3$; lean regression $\mathrm{p} \approx 0.23$ ).
} 
a senior executive at Fox distributors we interviewed contradicted this notion, suggesting that if anything distributors are tighter with their spending on advertising once the decision to cold-open is made (which happens late in the process, after the number of screens and most other variables have been determined). The executive's view was that distributors know cold-opened movies are not very good, and see high levels of ad spending on such movies as throwing good money after a bad movie. The industry also appears to typically set advertising budgets as a fixed proportion of production budgets (Vogel (2007) suggests one-half, an executive at Village Roadshow told us two-thirds). If these rules of thumb are true, then the production budget variable will pick up much of the omitted effect of dvertising on the cold opening decision, even if there is any. ${ }^{23}$

Another possible problem is that annoyed critics may give cold-opened movies lower critical ratings than they would have if the movies were screened in advance (perhaps as a way of punishing the distributors for making the movie unavailable). ${ }^{24}$ This explanation seems unlikely since critics pride themselves on objectivity (for example, they rarely mention in late reviews of cold opened movies that the movie was unavailable in advance). ${ }^{25}$ The fact that the cold opening premium on revenues is evident even when imdb user ratings are used instead of metacritic quality ratings also

\footnotetext{
${ }^{23} \mathrm{~A}$ regression of production budget on marketing budget, for the 445 movies that we have both types of budget data, has $R^{2}=0.496$, indicating advertising budgets are highly correlated with production budgets.

${ }^{24}$ Litwak (1986) mentions this idea when describing a cold opening.

${ }^{25}$ On their TV movie-review show Roger Ebert and Richard Roeper introduced the "Wagging Finger of Shame" awarded to cold opened movies. However, they did not do this to convey negative opinions about particular movies; they did it because they thought that shaming some movies would discourage the practice in general. They discontinued the 'award' when they felt it was not working (Germain, 2006). In one case, Roeper gave a cold-opened movie ("When a Stranger Calls") his video recommendation, a recommendation he would not have made if he was intent on being overly negative simply because a movie was cold-opened.
} 
rules out this hypothesis.

One way to test for an omitted-variable bias is to look at the log total box office of the U.K. and Mexico, and log of US video rental data. In these markets, the possible deception of cold opening on strategically naïve moviegoers should be less effective because movies are almost always released in the U.K. and Mexico after the initial U.S. release, and home video rentals are always later than U.S. box office releases. If information about the movie's quality is widely disseminated before these later releases, the cold opening effect should disappear in foreign and rental markets.

Table 3 reports the cold-opening coefficients (from a regression including all variables as in Table 2). There is apparently no cold opening premium in these two foreign markets and the rental markets. These results work against the hypothesis that the premium is due to an omitted-variable bias and is consistent with the hypothesis that some moviegoers are fooled by cold openings before information leaks out. ${ }^{26}$

Another way to check whether cold opened movies have any inherent differences in sensitivity to critic ratings is to examine the movies by genre. Comedies and suspense/horror movies account for $80 \%$ of cold openings, but only $54 \%$ of all movies (see Table 4 ). If fans of these genres have

\footnotetext{
${ }^{26}$ Another explanation is that moviegoers of cold-opened movies are less sensitive to critic reviews. Then the high turnouts for cold-opened movies have nothing to do with the opening, but just the fact that given identically low critic reviews, cold-opened movies turn out more viewers. This explanation may appear appealing as the correlation of critic reviews and user reviews for cold-opened movies while high (0.51) is much lower than the correlation of critic reviews and user reviews of non-cold opened movies (0.76). However, this relationship likely results from the fact that cold-opened movies create a smaller range of critic ratings $\left(\bar{x} \approx 25, s^{2} \approx 11\right)$. If we restrict non-cold opened movies to those with critic ratings under $40\left(\bar{x} \approx 29, s^{2} \approx 8\right)$ or above $60\left(\bar{x} \approx 70, s^{2} \approx 7\right)$, we find similar values for the correlation ( 0.51 and 0.53 , respectively).
} 


\begin{tabular}{|l|r|r|r|r|}
\hline & \multicolumn{4}{|c|}{ cold opening (dummy) } \\
\cline { 2 - 5 } dependent variable & coefficient & std error & \multicolumn{1}{c|}{ t-statistic } & $\begin{array}{c}\text { one-tailed } \\
\text { significance }\end{array}$ \\
\hline $\log$ total US box office & 0.154 & 0.090 & 1.710 & 0.044 \\
$\log$ total US rentals & -0.007 & 0.101 & -0.067 & - \\
$\log$ UK box office & -0.021 & 0.231 & -0.090 & - \\
\hline $\log$ Mexico box office & -0.001 & 0.150 & -0.010 & - \\
\hline
\end{tabular}

Table 3: The cold opening percentage premium (regression coefficient) in non-US box office markets (control variables included, but results not reported).

\begin{tabular}{|c|c|c|c|c|c|c|c|c|}
\hline Genre & \# Movies & $\begin{array}{l}\text { \# Cold } \\
\text { opened }\end{array}$ & $\begin{array}{c}\text { Percent } \\
\text { cold opened }\end{array}$ & $\begin{array}{c}\text { Avg } \\
\text { weekend } \\
\log (\mathrm{BO})\end{array}$ & $\begin{array}{c}\text { Avg } \\
\text { Metacritic } \\
\text { score }\end{array}$ & $\begin{array}{l}\text { Avg imdb } \\
\text { user rating }\end{array}$ & $\begin{array}{l}\text { Imdb-Meta } \\
\text { Correlation }\end{array}$ & $\begin{array}{c}\text { Cold } \\
\text { Dummy for } \\
\text { Weekend } \\
\log (\mathrm{BO})\end{array}$ \\
\hline Act/Adv & 143 & 5 & 0.03 & 3.827 & 48.2 & 5.91 & 0.79 & 0.165 \\
\hline Animated & 51 & 1 & 0.02 & 3.949 & 56.6 & 6.07 & 0.85 & -0.547 \\
\hline Comedy & 322 & 21 & 0.07 & 3.352 & 42.1 & 5.41 & 0.73 & 0.173 \\
\hline Doc & 3 & 0 & 0.00 & 2.351 & 58.0 & 5.63 & 0.87 & \\
\hline Drama & 145 & 3 & 0.02 & 3.240 & 50.5 & 6.28 & 0.69 & 0.229 \\
\hline Fant/Sci & 55 & 4 & 0.07 & 4.120 & 50.8 & 6.11 & 0.88 & 0.121 \\
\hline Susp/Horr & 137 & 25 & 0.18 & 3.334 & 41.4 & 5.70 & 0.74 & 0.077 \\
\hline Overall & 856 & 59 & 0.07 & 3.443 & 45.8 & 5.76 & 0.76 & 0.155 \\
\hline
\end{tabular}

Table 4: Data separated by movie genre

less sensitivity to bad reviews (suggested by Reinstein and Snyder, 2005), and are more likely to go to a movie that has low critic ratings than fans of other genres, then the cold opening premium could be a result of the selection of cold-opened movies into these genres. ${ }^{27}$

Table 4 shows that this is not the case. Throughout genres, moviegoers' correlation between critic reviews and self-reported reviews are all around 0.75 . The cold open premium is positive for all genres (6-21\%) except for the genre "animated" which is driven by a single movie, "Doogal." The cold opening premium is, apparently, not genre-specific.

Finally, our hypothesis is that limited iterated strategic thinking causes some moviegoers to be

\footnotetext{
${ }^{27}$ This explanation would not explain why distributors would be more likely to withhold bad news in genres where the intended audience is the least receptive to bad news.
} 
"tricked," overestimating the ex-ante quality of cold opened movies. These should be lower user reviews for cold-opened movies, holding everything else constant. Using imdb.com user data and the usual table 2 independent variables, we find that cold opened movies have an average rating 0.4 points (out of 10) lower than non-cold opened movies. The result is highly significant $(p<0.001)$.

In the next section we will develop two structural models of strategic thinking by moviegoers and distributors and estimate behavioral parameters which measure the degree of limited strategic thinking for both groups. If some of these models can successfully explain the cold opening premium with similar parameter values to what has been observed in other studies, that result is another piece of evidence that the premium is not due to an omitted variable, but instead reflects some limit on strategic thinking.

\section{The General Model}

In designing a model of movie viewing and distributor choice, the aim is to create a model that can be analyzed with box office data, but allows estimation of behavioral parameters of individual thinking. The model permits both distributors and moviegoers to be influenced by the choice and cognition of the other side. Recall that the initial regressions in Section 2 were not designed to understand the endogenous choice of distributors to cold open, and the likely reactions of moviegoers, but these behavioral models are.

To fix notation, assume that the distributor of movie $j$ and moviegoers both know movie characteristics $X_{j}$. The game form is simple: Distributors observe $q_{j}$ and then choose whether to open cold $\left(c_{j}=1\right)$ or to screen for critics in advance $\left(c_{j}=0\right)$. Moviegoers form a belief $E_{m}\left(q_{j} \mid c_{j}, X_{j}\right)$ 
about a movie that depends on its characteristics $X_{j}$ and whether it was cold opened $c_{j} .{ }^{28}$ Below we consider two models of belief formation which incorporate different types of limits on strategic thinking. Both include fully rational equilibrium as limiting cases.

The first assumption is that if a movie is screened to critics, its quality is then known to moviegoers. Quality could be known with noise and all results go through if moviegoers are risk-neutral:

Assumption 1. $E_{m}\left[q_{j} \mid 0, X_{j}\right]=q_{j}$.

To model moviegoing and distributor decisions jointly, we use a quantal response approach in which moviegoers and distributors choose stochastically according to either utilities or expected profits. Since we have no data on individual choices or demographic market-segment data, we use a representative-agent approach to model moviegoers. Assumption 2 is that moviegoer utility is linear in movie characteristics and expected quality, subtracting the ticket price.

Assumption 2. $U\left(X_{j}, E_{m}\left(q_{j} \mid c_{j}, X_{j}\right)\right)=\alpha E_{m}\left(q_{j} \mid c_{j}, X_{j}\right)+\beta X_{j}-\hat{t}+\epsilon_{j}$

where $\alpha$ and $\beta$ give the corresponding predictive utility associated with expected quality and other known characteristics of movies. The opportunity utility of not going to the movies is defined as zero. ${ }^{29}$ In the quantal response approach, probabilities of making choices depend on their relative utilities. We use a logit specification (e.g., McFadden, 1974). The probability that the representa-

\footnotetext{
${ }^{28}$ It is not crucial that moviegoers literally know whether a movie has been cold-opened or not (e.g., surveys are likely to show that many moviegoers do not know). The essential assumption for analysis is that beliefs are approximately accurate for pre-reviewed movies and formed based on some different behavioral assumption for cold-opened movies.

${ }^{29}$ This is without loss of generality because a constant term is included in the revenue regression, which in this model is equivalent to the estimated utility of not going to the movie.
} 
tive moviegoer will go to movie $j$ with characteristics $X_{j}$ and expected quality $E_{m}\left(q_{j} \mid c_{j}, X_{j}\right)$, at ticket price $\hat{t}^{30}$ is

$$
p\left(X_{j}, E_{m}\left(q_{j} \mid c_{j}, X_{j}\right)\right)=\frac{1}{1+e^{-\lambda_{m}\left(\alpha E_{m}\left(q_{j} \mid c_{j}, X_{j}\right)+\beta X_{j}-\hat{t}+\epsilon_{j}\right)}}
$$

where $\lambda_{m}$ is the sensitivity of responses to utility. Higher values of $\lambda_{m}$ imply that the higher-utility choice is made more often. At $\lambda_{m}=0$, choices are random. ${ }^{31}$ As $\lambda_{m} \rightarrow \infty$, the probability of choosing the option with the highest utility converges to one (best-response). ${ }^{32}$

Expected box-office revenues are assumed to equal the probability of attendance by a representative moviegoer, times the population size $N$ and ticket price $\hat{t}$, which yields $R\left(X_{j}, E_{m}\left(q_{j} \mid c_{j}, X_{j}\right)\right)=$ $N \hat{t} p\left(X_{j}, E_{m}\left(q_{j} \mid c_{j}, X_{j}\right)\right)$. Note that the distributor's choice of $c_{j}$ is assumed to enter the revenue

\footnotetext{
${ }^{30}$ The term $\hat{t}$ is the average US ticket price in midyear 2003 (recall box office revenues are in 2003 dollars). For an explanation of why movie ticket prices are not different for different movies see Orbach and Einav (2007) or for a more general explanation, Barro and Romer (1987).

${ }^{31}$ This model implies that if $\lambda_{m}=0$, the representative moviegoer will attend each movie in its first weekend with .5 probability. While that result may be unappealing, note that a multinomial specification (i.e, if $\lambda_{m}=0$, the representative moviegoer will go to the movies with .5 probability and which movie he goes to will depend on its underlying characteristics) would be much more complicated to calculate and also has unappealing results. For instance, movies that open alone each weekend should have much higher box office than those that open when three other movies do (which is generally not true).

Additionally, this point is moot. The later $\lambda_{m}$ estimates will be far from 0 (see Table A.4). As it turns out when one looks at equation 6 , it is apparent that it would require on average movies to make roughly $\$ 800$ million in their first weekend to push $\hat{\lambda}_{m}$ to 0 (because that parameter value suggests half the US population sees the movie). Instead this value can be thought of as an upper bound on movie revenue and a lower bound on rationality.

${ }^{32}$ See Luce and Raiffa (1957), Chen et al. (1997), McKelvey and Palfrey (1995, 1998).
} 
equation solely through its effect on moviegoer expectations of quality $E_{m}\left(q_{j} \mid c_{j}, X_{j}\right)$.

The distributor's decision to screen the movie $\left(c_{j}=0\right)$ or open it cold $\left(c_{j}=1\right)$ is also modeled by a stochastic choice function based on a comparison of expected profits from the two decisions. Given assumption 1 , the revenue from screening is $R\left(X_{j}, q_{j}\right)$ and the revenue from cold opening is $R\left(X_{j}, E_{m}\left(q_{j} \mid 1, X_{j}\right)\right)$. Given the same logit choice specification as for moviegoers, the probability of a distributor opening the movie cold is therefore given by assumption 3 ,

Assumption 3. $\pi\left(X_{j}, q_{j}\right)=1 /\left(1+\exp \left[-\lambda_{d}\left[R\left(X_{j}, E_{m}\left(q_{j} \mid 1, X_{j}\right)\right)-R\left(X_{j}, q_{j}\right)\right]\right]\right)$

where $\lambda_{d}$ is the sensitivity of distributor responses to expected revenue. ${ }^{33}$

The logic of the model and our data (see Section 2 and Table 2) suggest that cold opening most strongly affects the first weekend's revenue (which may then affect cumulative revenue). Therefore, we use the first weekend's revenue to calibrate the models' revenue equations and distributor decisions in the next section. Our probability and utility functions given in assumption 2 and equation 2 are based on the moviegoers' behavior in the first weekend. ${ }^{34}$

\section{Two Behavioral Models of Limited Strategic Thinking}

The crucial behavioral questions are what moviegoers believe about the quality of a movie that is cold-opened-i.e., what is $E_{m}\left(q_{j} \mid 1, X_{j}\right)$ ? — and how those expected beliefs influence the distribu-

\footnotetext{
${ }^{33}$ In many previous applications of these games to experimental datasets the response sensitivity parameters $\lambda$ are the same since game payoffs are on similar payoff scales. We use two separate parameters here for moviegoers and distributors, $\lambda_{m}$ and $\lambda_{d}$, because the payoffs are on the order of dollar-scale utilities for moviegoers and millions of dollars for distributors.

${ }^{34}$ Results are similar when total box office is used.
} 
tor's probability of choosing a cold opening, which is $\pi\left(X_{j}, q_{j}\right)$.

This section compares two models of beliefs: Cursed equilibrium (Section 4.1), and cognitive hierarchy (Section 4.2). Each model requires that moviegoers and distributors optimize (stochastically) based on their belief about the other's actions, but those beliefs might be limited in strategic sophistication. In this way the model allows the decision of distributors to cold open to be endogenously related to moviegoers' attendance of cold opened movies, which is in turn driven by moviegoers' beliefs about what cold opening implies about quality. This structure represents an improvement on the initial regressions in Section 2), and is a tool for gauging how well behavioral models developed to explain experimental data may work in a field setting.

In cursed equilibrium (Section 4.1), moviegoers' beliefs about the quality of a cold-opened movie are a weighted average of unconditional overall average quality (with weight $\chi$ ) and the rationally-expected quality that fully anticipates distributors' decisions (with weight $1-\chi$ ). ${ }^{35}$ The

\footnotetext{
${ }^{35}$ It is tempting to interpret $\chi$ as a fraction of people who are uninformed about reviews because finding out about reviews is costly (as discussed in section 2.1). This interpretation is not tested by our empirical procedure, because we use the empirical quality-revenue relation for reviewed (i.e., non-cold-opened) movies as an input to then estimate $\chi$. A proper implementation of the theory that some moviegoers don't find out anything about reviews requires inclusion of a parameter measuring the fraction of uninformed moviegoers, which influences both the quality-revenue equation for reviewed movies, and the estimated value of $\chi$ (which will mistakenly include that fraction). Such a model is not well-identified without more information of how informed moviegoers are or how many are not thinking strategically, which might be measured directly in surveys or methods to classify people into types. However, in our specific structural framework, box office revenues are not linear in expected beliefs (through assumption 2). So a model in which there are a fraction $\chi$ of people who use average quality for cold-opened movies, and a fraction $1-\chi$ who form rational expectations is not exactly equivalent. (The difference is that between a nonlinear probability function of a weighted average and a weighted average of nonlinear probabilities.)
} 
parameter $\chi$ is a measure of the degree of naïveté in the moviegoers' strategic thinking (i.e., to what extent beliefs about cold-opened movies are biased toward average quality).

In the cognitive hierarchy $(\mathrm{CH})$ approach (Section 4.2), there is a hierarchy of levels of strategic thinking. The lowest-level thinkers do not think strategically at all, and higher-level thinkers bestrespond to correctly anticipated choices of lower-level thinkers. For parsimony, the percentages of players at different levels in the cognitive hierarchy are characterized by a Poisson distribution with mean thinking-level parameter $\tau$.

Importantly, both models allow full rationality as a limiting case of their behavioral parameters. Full rationality corresponds to $\chi=0$ in cursed equilibrium and $\tau \rightarrow \infty$ in $\mathrm{CH}$. In the former case, full rationality corresponds to a quantal response equilibrium (McKelvey and Palfrey, 1995, 1998). Therefore, estimates derived from the data will indicate the degree of moviegoer rationality as parameterized in these two ways.

\subsection{Cursed Equilibrium}

Eyster and Rabin (2005) created a model of "cursed equilibrium" to explain stylized facts like the winner's curse in auctions, and other situations where some agents do not seem to infer the private information of other players from those players' actions. Their idea is that such an incomplete inference is consistent with agents not appreciating the degree to which other players' actions are conditioned on information. ${ }^{36}$

In this context, for every cold opened movie, all moviegoers believe that the movie has quality

\footnotetext{
${ }^{36}$ An alternative to the cursed equilibrium model, the analogy-based expectation equilibrium model (Jehiel, 2005; Jehiel and Koessler, 2008) can also model partial sophistication from an equilibrium viewpoint. Because that model is less parsimonious than the cursed equilibrium model, it will not be used in this paper's analysis.
} 
equal to some weighted average of the rational expectation of movie quality (given distributor decisions) and the average of all movies (i.e., ignoring any information conveyed by the cold opening decision). That is,

$$
E_{m}^{c e}\left(q_{j} \mid 1\right) \equiv\left(1-\chi_{m}\right) E_{m}^{r e}\left(q \mid X_{j}, 1\right)+\chi_{m} \bar{q}
$$

where $E_{m}^{r e}\left(q \mid X_{j}, 1\right)$ reflects rational expectations about distributor decisions.

The rational expectation belief, $E_{m}^{r e}\left(q_{j} \mid 1, X_{j}\right)$, about the quality of an unscreened movie with characteristics $X_{j}$ is

$$
\begin{aligned}
& E_{m}^{r e}\left(q_{j} \mid 1, X_{j}\right)=\sum_{q=0}^{100} q P\left(q \mid X_{j}, 1\right) \\
& =\frac{\sum_{q=0}^{100} q P\left(1, X_{j}, q\right)}{P\left(1, X_{j}\right)} \quad \text { (Bayes' rule) } \\
& =\frac{\sum_{q=0}^{100} q P\left(1, X_{j}, q\right)}{\sum_{q=0}^{100} P\left(1, X_{j}, q\right)} \quad \text { (laws of probability) } \\
& =\frac{\sum_{q=0}^{100} q P\left(1 \mid X_{j}, q\right) P\left(X_{j}, q\right)}{\sum_{q=0}^{100} P\left(1 \mid X_{j}, q\right) P\left(X_{j}, q\right)} \quad \text { (laws of probability) } \\
& =\frac{\sum_{q=0}^{100} q P\left(1 \mid X_{j}, q\right) P\left(X_{j}\right) P(q)}{\sum_{q=0}^{100} P\left(1 \mid X_{j}, q\right) P\left(X_{j}\right) P(q)} \quad \text { (independence assumption) } \\
& =\frac{\sum_{q=0}^{100} q \pi\left(X_{j}, q\right) P(q)}{\sum_{q=0}^{100} \pi\left(X_{j}, q\right) P(q)} \quad \text { (definition in (A3)). }
\end{aligned}
$$

Intuitively, for agents to form an expectation about the quality of a cold opened movie $E_{m}^{r e}\left(q_{j} \mid 1, X_{j}\right)$, they must consider all possible levels of quality that a movie could have (hence the summations over all integers in $[0,100])$, and the conditional probability that the movie would be of the hypothesized quality given its characteristics and the fact that a distributor decided to cold open it with probability $P\left(q \mid 1, X_{j}\right)$ (which is equal to $\pi\left(q \mid 1, X_{j}\right)$, the actual probability). This derivation uses the laws of probability, and the crucial assumption that the probability of any movie's quality 
level, $P(q)$, is independent from the probability of it having any other characteristics $\left(P\left(X_{j}\right)\right),{ }^{37}$ then a cold opened movie's expected quality, $E_{m}^{q r e}\left(q_{j} \mid 1, X_{j}\right)$, only depends on the joint probability of a distributor cold opening a movie with given characteristics and quality $\left(\pi\left(X_{j}, q\right)\right)$, and the frequency of quality ratings $(P(q))$. Independence is a helpful simplification because without it, distributor decisions would depend on quality and on the entire vector of characteristics, which creates too many decision probabilities to estimate reliably. From this transformation we are able to calculate $E_{m}^{q r e}\left(q_{j} \mid 1, X_{j}\right)$ if $\pi\left(X_{j}, q\right)$ is known.

The cold opening probabilities $\pi\left(X_{j}, q\right)$ depend on estimated revenues from opening the movie cold or screening it (and revealing its quality, assuming (A1)). We use a transformation, then regression, to estimate the revenue as a function of $X_{j}$ and $q$. The revenue equation (defined in previous section) is

$$
\begin{aligned}
R\left(X_{j}, E_{m}\left(q_{j} \mid c_{j}, X_{j}\right)\right) & =N \hat{t} p\left(X_{j}, E_{m}\left(q_{j} \mid c_{j}, X_{j}\right)\right) \\
& =N \hat{t} /\left[1+e^{-\lambda_{m}\left(\alpha E_{m}\left(q_{j} \mid c_{j}, X_{j}\right)+\beta X_{j}-\hat{t}+\epsilon_{j}\right)}\right]
\end{aligned}
$$

Rearranging terms and taking a logarithm, yields a specification which is easy to estimate because it is linear in characteristics $X_{j}$ and expected quality $E_{m}\left(q_{j} \mid c_{j}, X_{j}\right)$,

$$
\log \left(\frac{R\left(X_{j}, E_{m}\left(q_{j} \mid c_{j}, X_{j}\right)\right)}{N \hat{t}-R\left(X_{j}, E_{m}\left(q_{j} \mid c_{j}, X_{j}\right)\right)}\right)=-\lambda_{m}\left(\alpha E_{m}\left(q_{j} \mid c_{j}, X_{j}\right)+\beta X_{j}-\hat{t}+\epsilon_{j}\right)
$$

\footnotetext{
${ }^{37}$ Appendix B, Table A.3 shows the intercorrelation matrix. There is only one variable which has a correlation with quality higher than .20 -namely, the budget $(r=.28)$. Therefore, the assumption of independence in (3) is not a bad approximation.
} 
Note that this rational expectation computation is recursive: Moviegoers' beliefs about the quality of cold opened movies depend on which movies the distributors choose to cold open (through equation 4). But the distributors' choice to cold open depends on moviegoers' beliefs about the quality of cold opened movies (through assumption 3).

Because of this recursive structure, we estimate the model using an iterative procedure (see Appendix $\mathrm{C}$ for details). The procedure first uses the large number of screened movies (where quality is assumed to be known to moviegoers by (1)) to estimate regression parameters that forecast revenues conditional on quality in (6). Then movie-specific expected qualities for all cold opened movies are imputed using a maximum-likelihood procedure that chooses a distributor response sensitivity $\lambda_{d}$ which explains actual distributor decisions best and satisfies the assumption that moviegoers' beliefs are a $\chi$-weighted mixture of rational expectations and naive beliefs (equation 6). These inferred expected qualities are then added to qualities of all movies to re-estimate (6) and the process iterates until parameters converge. Convergence means that parameters have been found such that both the representative moviegoer and the distributors best-respond (stochastically) and the moviegoer rational-expectations constraint on cold-opened movies (4) is satisfied.

To find the best-fitting $\chi$, the procedure is repeated using a grid-search over values between 0 and 1 , and the best-fitting $\chi$ is found (using a maximum likelihood criterion over all distributors' release decisions). That is, given the 856 (797 screened, 59 cold) release decisions in our dataset, if distributors were best responding to the a curse of moviegoers (knowing moviegoers characteristics for movies and quantal response parameter $\lambda_{m}$ ), the maximum likelihood value of that curse is $\chi^{*}$.

Our best fitting value is $\chi^{*}=0$, largely because this value is based on distributors decisions. This is the model's only way of accounting for the two stylized facts- viz., (i) there are few cold openings, but (ii) there is a substantial box office premium. Within the restricted structure of the 
model, the paucity of cold openings implies $\chi_{d}$ is low (i.e., distributors think moviegoers, have little curse, and hence will believe cold-opened movies are terrible, which is why they open cold so rarely). Given that estimate, the rational expectation of cold-opened movie quality is very low, so to explain the box office premium the weight on the rational expectation term must be low. Note that this is the same as fitting quantal response equilibrium (McKelvey and Palfrey, 1995, 1998).

Table A.4 shows the regression results from six iterations from this process (which stopped according to the step 6 convergence definition in Appendix C). The r-squared value, 0.682, shows our model has a reasonable fit with the data. The final log likelihood value, -205.7 implies that the (geometric) meancorrectly-predicted probability of actual decisions for all movies is 0.79 . This predicted probability is much better than chance guessing (0.5) but is only a little better than simply guessing that all movies have a cold opening probability equal to the $7 \%(=59 / 856)$ base rate, which yields a log-likelihood value of -211.62 , and a mean correctly predicted probability 0.78 . Standard error estimates, determined by 100 bootstraps of this process, are shown in Table 8 and will be discussed in Section 4.3.

After calculating $\chi^{*}=0$, we calculated an additional parameter for moviegoers, $\chi_{m}$, given the quantal response parameters $\lambda_{m}, \lambda_{d}$ and $\chi^{*}$, based on cold opened movies' first weekend revenues. The best-fitting value is $\widehat{\chi_{m}}=.922,{ }^{38}$ indicating a high degree of curse (recall that $\chi_{m}=0$ is no curse). That is, since the estimated correct expectation $E_{m}^{r e}\left(q \mid X_{j}, 1\right)$ for cold opened movies is low $\left(\overline{E_{m}(q \mid 1)}=25\right)$, and average overall quality is much higher $(\bar{q}=48)$ the representative moviegoer is cursed in believing that quality of a cold opened movie is roughly $46\left(=48 \widehat{\chi_{m}}+25\left(1-\widehat{\chi_{m}}\right)\right)$,

\footnotetext{
${ }^{38}$ We feel the parameter $\chi^{*}=0$ is the true estimate from the cursed equilibrium model. If we began the iterative process with $\chi^{*}=0$ it would converge with $\chi^{*}=0$, if we began the process with $\chi^{*}=0.922$ it would converge with $\chi^{*}=0$.
} 
much closer to the average quality of all movies than the actual average quality of cold-opened movies. Cursed moviegoers vastly overestimate the quality of movies that are opened cold.

Since box-office revenues are increasing in quality, the fact that cursed moviegoers overestimate the quality of cold opened movies is consistent with the box office premium found in the basic regressions in Section 2. Indeed, the best-fitting cursed parameter estimate given the expectations found in the previous model, of $\hat{\chi}_{m 1}=.922$, predicts an average log box office premium on weekend box office of 0.33 (an increase in revenue of 33\%). This value is considerably higher than $15 \%$ estimate determined from our initial regression-i.e., it appears that the model implies too little rationality of moviegoers, and too large a box office premium compared to the revenue effect from regression (see Appendix B for more detail). However, the curse estimate is close to the value $(\chi=.8)$ estimated by Eyster and Rabin on experimental data from Forsythe et al. (1989) on agents' "blind bidding" for objects of unknown value.

\subsection{A Cognitive Hierarchy Model}

Cognitive hierarchy or level- $k$ models assume the population is composed of individuals that do different numbers of steps of iterative strategic thinking. The lowest level (0-level) thinkers behave heuristically (perhaps randomly) and $k$ level thinkers optimize against $k-1$ type thinkers. ${ }^{39}$ Zerolevel thinkers, such as moviegoers, do not think about the distributor's actions of cold opening a movie. For any cold-opened movie they infer the movie's quality $E_{m}^{0}\left(q_{j} \mid X_{j}, 1\right)$ at random ${ }^{40}$ by

\footnotetext{
${ }^{39}$ This classification differs from some other versions of the cognitive hierarchy model (Camerer et al., 2004) which suggests $k$ level thinkers optimizes against a distribution of $0,1, \ldots k-1$ level thinkers.

${ }^{40}$ In many games, assuming that 0 -level players choose randomly across possible strategies is a natural starting point. However, the more general interpretation is that 0-level players are simple, or heuristic, rather than random. For
} 
selecting any integer on $[0,100]$ with equal probability. They will go to any movie with probability defined as an analogue of equation (2)

$$
p_{0}\left(X_{j}, E_{m}^{0}\left(q_{j} \mid c_{j}, X_{j}\right)\right)=\sum_{q=0}^{100}(1 / 101) \frac{1}{1+e^{-\lambda_{m}\left(\beta X_{j}+\alpha q-\hat{t}+\epsilon_{j}\right)}}
$$

where $E_{m}^{0}\left(q_{j} \mid c_{j}, X_{j}\right) \sim U[0,100]$. Similarly, a 0-level distributor will cold open movies at random, that is,

$$
\pi_{0}\left(q_{j}, X_{j}\right)=1 / 2
$$

A 1-level moviegoer knows 0-level distributors cold open movies at random, and assumes all distributors behave in this manner. For each movie he calculates the expected quality given it has been cold opened as

$$
\begin{aligned}
E_{m}^{1}\left(q \mid X_{j}, 1\right) & =\frac{\sum_{q=0}^{100} q P(q) \pi_{0}\left(q, X_{j}\right)}{\sum_{q=0}^{100} P(q) \pi_{0}\left(q, X_{j}\right)} \\
& =\frac{\sum_{q=0}^{100} q P(q) \frac{1}{2}}{\sum_{q=0}^{100} P(q) \frac{1}{2}} \\
& =\bar{q} .
\end{aligned}
$$

example, in "hide-and-seek" games a natural starting point is to choose a "focal" strategy (see Crawford and Iriberri (2007a)). In our game, random choice by moviegoers would mean random attendance at movies. That specification of 0-level play doesn't work well because it generates far too much box office revenue. Another candidate for 0-level moviegoer play is to assume a cold-opened movie has sample-mean quality $\bar{q}$. For technical reasons, that does not work well either. It is admittedly not ideal to have special $a d$ hoc assumptions for different games. Eventually we hope there is some theory of 0-level play that maps the game structure and a concept of simplicity or heuristic behavior into 0-level specifications in a parsimonious way. 
A 1-level distributor expects all moviegoers to behave like 0-level moviegoers. They will assign quality ratings to cold-opened movies at random from the uniform $U[0,100]$ distribution. The 1-level distributor will therefore cold-open movie $j$ with probability

$$
\pi_{1}\left(q_{j}, X_{j}\right)=1 /\left(1+\exp \left[\lambda_{d}\left(\sum_{q=0}^{100}(1 / 101) R\left(X_{j}, q\right)-R\left(X_{j}, q_{j}\right)\right)\right]\right) .
$$

Proceeding inductively, for any strategic level $k$, the values $E_{m}^{k-1}\left(q \mid 1, X_{j}\right)$ and $\pi_{k-1}\left(q_{j}, X_{j}\right)$ are computed from response to k-1 level type beliefs and actions. The k-level distributor and moviegoer have probabilities and beliefs

$$
\pi_{k}\left(q_{j}, X_{j}\right)=1 /\left(1+\exp \left[\lambda_{m}\left(R\left(X_{j}, E_{k-1}\left(q \mid X_{j}, 1\right)\right)-R\left(X_{j}, q_{j}\right)\right)\right]\right)
$$

and

$$
E_{k}\left(q \mid X_{j}, 1\right)=\frac{\sum_{q=0}^{100} q P(q) \pi_{k-1}\left(q, X_{j}\right)}{\sum_{q=0}^{100} P(q) \pi_{k-1}\left(q, X_{j}\right)}
$$

which leads to moviegoing probability

$$
p_{k}\left(X_{j}, E_{m}^{k}\left(q_{j} \mid c_{j}, X_{j}\right)\right)=\frac{1}{1+e^{-\lambda_{m}\left(\beta X_{j}+\alpha E_{m}^{k}\left(q_{j} \mid c_{j}, X_{j}\right)-\hat{t}+\epsilon_{j}\right)}}
$$

where every level-k distributor and moviegoer is playing a quantal response to the level-k-1 moviegoer and distributor respectively.

As an example, Table 5 shows moviegoer-inferred quality and distributor probability of cold opening for the movie When a Stranger Calls, for various levels of thinking and their proportions within the population with $\lambda_{d}=7.085$ (a figure estimated from the data, see Table A.5). 


\begin{tabular}{|r|r|r|}
\hline $\mathrm{k}$ & $\mathrm{E}_{\mathrm{k}}(\mathrm{q} \mid \mathrm{Xj}, 1)$ & $\pi_{\mathrm{k}}\left(\mathrm{q}_{\mathrm{j}}, \mathrm{X}_{\mathrm{j}}\right)$ \\
\hline 0 & $\mathrm{U}[0,100]$ & 0.50 \\
1 & 48.12 & 1.00 \\
2 & 40.79 & 1.00 \\
3 & 34.28 & 1.00 \\
4 & 29.40 & 1.00 \\
5 & 24.66 & 0.94 \\
6 & 20.97 & 0.10 \\
7 & 17.40 & 0.01 \\
8 & 14.73 & 0.00 \\
9 & 12.20 & 0.00 \\
10 & 10.26 & 0.00 \\
\hline
\end{tabular}

Table 5: Expected quality of When a Stranger Calls $(q=27)$ given it is cold opened by level- $k$ moviegoer and probability it is cold opened by level- $k$ distributor in $\mathrm{CH}$ with QR model $\left(\lambda_{d}=\right.$ 7.085).

Notice that a 0-level distributor cold opens movies at random. Thus a 1-level moviegoer, optimizing against such distributor, believes that cold opened movies have quality (48.12), the average quality of all movies (see equation 9). Then a 2-level distributor, knows that a 1-level moviegoer's belief in cold opened quality is much higher than actuality $(q=27)$. Since quality is preferred by moviegoers, such distributor is very likely to cold open the movie (he will only release it given a quantal response tremble, which depends on the other characteristics of the movie $\left(X_{j}\right)$ ). The same can be said for for all level 1-5 distributors. However if a moviegoer is level 5 or above, he believes a cold opened movie has lower quality than 27 , thus distributors who optimize against such moviegoers (levels 6+) are unlikely to cold open a movie of quality 27.

The cognitive hierarchy model of Camerer et al. (2004), based on lots of structurally different experimental games, suggests that the proportion of thinkers in the population is often well approximated by a one-parameter Poisson distribution with mean $\tau$,

$$
P(x=n \mid \tau)=\tau^{n} e^{-\tau} / n !
$$


where $\tau$ is the average number of steps of strategic thinking. ${ }^{41}$

Since the cognitive hierarchy model is only a partial equilibrium model (i.e., only the highest types have accurate beliefs), it is sensible to the average level of distributor and moviegoer thinking to differ. For this reason we will define two separate $\tau$ parameters: $\tau_{m}$ will be the mean number of moviegoer steps of strategic thinking, and $\tau_{d}$ will be the mean number of distributor steps of strategic thinking. The limiting result $\tau_{d}=\tau_{m}=\infty$ implies both are best responding to each other and is equivalent to quantal response equilibrium.

To determine $\mathrm{QR}$ parameters $\left\{\lambda_{d}, \lambda_{m}\right\}$ and additional $\mathrm{CH}$ parameters $\left\{\tau_{d}, \tau_{m}\right\}$, we use an iterative procedure for estimating values similar to the cursed equilibrium procedure. The procedure is much easier, however, because level-k player behavior is determined by level-k-1 behavior. The iteration is a "do loop" for specific $\lambda_{m}, \lambda_{d}$ values, which is truncated at high levels of $k(k>40)$ where the percentage of high level- $k$ players is very small (which depends on $\tau$ ). Looping through for various $\lambda_{m}, \lambda_{d}$ makes it easy to then grid-search over the $\lambda$ values and find best-fitting values of both $\tau$ and $\lambda$.

Table A.5 shows the results of the iterative process for the $\mathrm{CH}$ model with $\mathrm{QR}$. The process stopped after six iterations with a log likelihood value of -166.2 , which is a significant improvement over the asymmetric cursed model $(-205.7) .{ }^{42}$

Note that in the specification with identical values of mean thinking level $\tau$, the estimated value of $\hat{\tau}_{m}={\hat{\tau_{d}}}^{*}=1.12$. This is lower than in many experimental studies (often 1-2) but is in the

\footnotetext{
${ }^{41}$ All Poisson distributions are determined by one parameter $\tau$, which is both the mean and variance of the distribution. Thus $\tau$ is also the variance of the number of steps of strategic thinking.

${ }^{42}$ The value for $\lambda_{d}$ (7.085) is also much greater than for the cursed equilibrium $\left(\lambda_{d}=1.345\right)$, but this difference reflects an unknown mixture of scale differences and differences in response sensitivity.
} 


\begin{tabular}{|c|c|c|c|c|}
\hline & & $\begin{array}{c}\text { mean predicted cold } \\
\text { opened weekend box } \\
\text { office }(\mathrm{N}=59)\end{array}$ & $\begin{array}{c}\text { predicted weekend } \\
\text { cold opening } \\
\text { premium }\end{array}$ & $\begin{array}{c}\text { (Average squared } \\
\text { difference in millions } \\
\$)^{1 / 2}\end{array}$ \\
\hline QRE & $\lambda_{\mathrm{m}}=1.288$ & 6.73 & $-5.47 \%$ & 6.00 \\
$(0.04)$ & $3.31)$ & $(0.09)$ \\
\hline \multirow{2}{*}{ Cursed Equilibrium } & $\chi_{\mathrm{m}}=0.922, \lambda_{\mathrm{m}}=1.288$ & 9.46 & $33.32 \%$ & 3.86 \\
& & $(0.08)$ & $(0.80)$ & $(0.05)$ \\
\hline \multirow{2}{*}{ Cognitive Hierarchy k-1 } & $\tau_{\mathrm{m}}=1.12, \lambda_{\mathrm{m}}=1.302$ & 8.96 & $35.70 \%$ & 5.64 \\
& & $(0.12)$ & $(1.20)$ & $(0.06)$ \\
\hline \multirow{2}{*}{ Random } & $\mathrm{E}(\mathrm{q}) \sim \mathrm{U}[0,100]$ & 11.44 & $63.56 \%$ & 5.74 \\
& & $(0.09)$ & $(0.83)$ & $(0.06)$ \\
\hline Actual Data & - & 20.63 & $14.70 \%$ & - \\
\hline
\end{tabular}

Table 6: Comparison of the three behavioral models for moviegoer predictions with bootstrapped standard errors $(N=100)$. The last column is the square root of the average of the squared difference between actual box office (in millions $\$$ ) and predicted box office (in millions $\$$ ).

ballpark, ${ }^{43}$ of estimates from experimental games $(\hat{\tau} \approx 1.5)^{44}$ and for field data the initial week of Swedish LUPI lotteries ( $\hat{\tau}=2.98$, Östling et al., (2007)) and managerial IT decisions $(\hat{\tau}=2.67$, Goldfarb and Yang (2007)). However, the common- $\tau$ estimation implies an average cold opening box office premium of $35.7 \%$ (Table 6), which, like the estimate for the cursed model, is positive but is much higher than the regression estimate.

\footnotetext{
${ }^{43}$ The objective function (sum of squared residuals) is rather flat in the vicinity of the best-fitting $\tau_{m}$, so higher values from $2-4$ give comparable fits to $\hat{\tau}_{m}^{*}=1.12$. An ex ante prediction based on $\tau=1.5$ from lab data would forecast reasonably well in this field setting.

${ }^{44}$ Crawford and Iriberri (2007a, 2007b) estimate a level-k model for auctions and hide-and-seek games respectively. They do not use a single Poisson parameter, but most of their classifications are for level 1 thinkers and level 2 second most, which would be most consistent with a Poisson parameter between 1-2.
} 


\begin{tabular}{|c|c|c|c|c|c|}
\hline model & parameter estimates & $\begin{array}{c}\log \\
\text { likelihood }\end{array}$ & $\begin{array}{c}\text { mean } \\
\text { correct (of } \\
856)\end{array}$ & $\begin{array}{c}\text { standard } \\
\text { deviation } \\
\text { correct }\end{array}$ & $\begin{array}{c}\text { no. } \\
\text { predicted to } \\
\text { open cold }\end{array}$ \\
\hline QRE & $\lambda_{d}=1.345$ & $\begin{array}{c}-205.76 \\
(2.16) \\
\end{array}$ & $\begin{array}{c}737.28 \\
(1.70) \\
\end{array}$ & $\begin{array}{r}7.37 \\
(0.07) \\
\end{array}$ & $\begin{array}{l}113.11 \\
(2.10) \\
\end{array}$ \\
\hline Cursed Equilibrium & $\lambda_{\mathrm{d}}=1.345, \chi=0$ & $\begin{array}{c}-205.76 \\
(2.16) \\
\end{array}$ & $\begin{array}{l}737.28 \\
(1.70) \\
\end{array}$ & $\begin{array}{c}7.37 \\
(0.07) \\
\end{array}$ & $\begin{array}{l}113.11 \\
(2.10) \\
\end{array}$ \\
\hline Cognitive Hierarchy k-1 & $l_{\mathrm{d}}=2.755, \tau_{\mathrm{d}}=8.550$ & $\begin{array}{c}-166.23 \\
(2.37)\end{array}$ & $\begin{array}{l}772.22 \\
(0.83)\end{array}$ & $\begin{array}{c}6.10 \\
(0.03) \\
\end{array}$ & $\begin{array}{l}61.73 \\
(1.09) \\
\end{array}$ \\
\hline Base Rate & $p=59 / 856$ & $\begin{array}{c}-214.73 \\
(2.21)\end{array}$ & $\begin{array}{l}740.55 \\
(1.47)\end{array}$ & $\begin{array}{c}7.41 \\
(0.05)\end{array}$ & $\begin{array}{l}59.00 \\
(0.85)\end{array}$ \\
\hline
\end{tabular}

Table 7: Predictions of cold opening choices of distributors with bootstrapped standard errors $(N=100)$. Each model provides a probability that a given movie will be cold opened. When compared with actual data, there is a probability that the model would correctly predict all actual decisions correct (log likelihood), an expected number of cold opening decisions the movie would predict correctly (mean correct), and the standard deviation of the number that model would predict correctly.

\subsection{Comparing Distributor Estimation across Models}

Table 8 provides standard error estimates from 100 random bootstraps of the data set for each parameter and each model. These bootstrapped samples are then used to give standard error estimates for comparative statistics between the three models in Tables 6 and 7. Among other things, Table 8 indicates the cognitive hierarchy model with quantal response fits distributor decisions (in terms of log likelihood) significantly better than the other models.

Another thing to note is that most of the cursed model bootstraps have a best-fitting $\chi$ value of 0. Thus the initial finding of common moviegoer curse and distributor expectation of moviegoer curse at $\hat{\chi}=0$ (equivalent to QRE) was not an aberration. However, standard errors indicate that for a few bootstrapped estimates, the best fitting $\chi$ was not zero. For $\chi_{m}$ the estimates indicate a high degree of curse with some variation.

Table 6 compares best-fitting parameter values in sums of squared residuals (for moviegoer 


\begin{tabular}{|c|c|c|c|}
\hline & QRE & Cursed Eq & CH with QR \\
\cline { 2 - 4 }$\lambda_{m}$ & 1.288 & 1.288 & 1.302 \\
$(0.005)$ & $(0.005)$ & $(0.004)$ \\
\hline$\lambda_{d}$ & 1.345 & 1.345 & 7.085 \\
& $(0.018)$ & $(0.018)$ & $(30.299)$ \\
\hline$\chi_{m}$ & - & 0.922 & - \\
\hline & & $(0.008)$ & \\
\hline$\chi^{*}$ & - & 0.000 & - \\
\hline & & $(0.001)$ & \\
\hline$\tau_{\mathrm{m}}$ & - & - & 1.120 \\
$\tau_{d}$ & - & - & $(0.121)$ \\
\hline & & & $(0.567$ \\
$\mathrm{E}_{\mathrm{m}}(\mathrm{q} \mid \mathrm{Xj}, 1)$ & $(0.315)$ & $(0.315)$ & $(0.587)$ \\
\hline & -205.712 & -205.712 & -166.232 \\
$\log \mathrm{MLE}$ & $(2.134)$ & $(2.134)$ & $(2.126)$ \\
\hline
\end{tabular}

Table 8: Parameter estimates of models with bootstrapped standard errors $(N=100)$.

Note: $\chi^{*}$ denotes result where moviegoers' curse and distributors' beliefs about moviegoers are the same.

decisions). The non-equilibrium cursed model predicts the box office revenues of cold opened movies best in terms of deviations from actual data; the cognitive hierarchy model fits second best. This is not surprising since both models predict a box office premium. Even a prediction that moviegoers assume uniformly random quality to cold opened movies (all 0-level thinkers) fits the data better than the rational alternative, QRE model, which assumes correct expectations for cold opened quality.

For distributor decisions (Table 8) the best fitting equilibrium cursed parameter is zero, so the cursed and rational alternative, QRE models perform identically (because with $\chi^{*}=0$, the models are equivalent). In cursed models, moviegoers and distributors are allowed to have non-Nash expectations, but distributors are required to best respond to them. The results suggest that given distributors must best respond to any degree of moviegoer curse, a model with moviegoers having correct expectations of movie quality fits the data best (that is, no expected moviegoer curse would 
explain the data better).

The $\mathrm{CH}$ model improves a little bit on the predictions of the cursed model. The key to its relative success is that the model estimates a low $\tau$ for moviegoers $\left(\hat{\tau}_{m}=1.12\right.$, close to experimental estimates of $\tau$ around 1.5-2.5) but the distributor $\tau_{d}$ is much higher (8.5). These parameters express the intuition that some moviegoers are easily fooled-they think cold openings are close to random—but distributors do not think moviegoers are so easily fooled, which is the models way of explaining why so few movies are cold-opened given the box office premium.

The $\mathrm{CH}$ model also predicts the most number of opening decisions correctly because its high $\tau_{d}$ predicts very few movies will be cold opened the higher $\lambda_{d}$ predicts some movies will be cold opened because of noise. The bootstrapped standard errors show these results are reasonably robust and do not depend on only a few data points. Importantly, the bootstrapped standard error around the mean bootstrapped estimate $\tau_{m}=1.120$ is 0.121 . This estimated $\tau$ for moviegoers is less than the average steps of thinking value found in most experiments (1.5), but is not much less. The estimate is also significantly different than random perception of quality $\left(\tau_{d}=0\right)$ or fully rational perception $\left(\tau_{d} \rightarrow \infty\right)$. The large improvement in log likelihood compared to the cursed model also suggests the $\mathrm{CH}$ model is a more reasonable overall explanation. All models are also an improvement over the baseline case which predicts that all movies to be cold-opened with the same probability (.07).

Finally, an entirely different explanation for the distributors' behavior is that distributors do not cold open enough because they are optimistic about their movie quality. ${ }^{45}$ For example, suppose that they think moviegoers have no curse (i.e., $\chi_{d}=0$ ) but they think their movie's quality is

\footnotetext{
${ }^{45}$ We thank Cade Massey for this insightful idea. Optimism has also been studied in economics by Camerer and Lovallo (1999), Brunnermeier and Parker (2005), and Mayraz (2008).
} 
a weighted average of its true quality and the top quality of 100 . That is, $E_{d}\left(q_{j}\right)=100 \zeta_{d}+$ $q_{j}\left(1-\zeta_{d}\right)$. If we use this perceived quality in lieu of the true quality and repeat the analysis, the best-fitting values are $\left\{\hat{\lambda}_{d}, \hat{\zeta}_{d}\right\}=\{0.183,0.283\}$. The associated log-likelihood is -175.057 , a substantial improvement over the no-optimism $\left(\tilde{\zeta}_{d}=0\right)$ fit of -204.20 . So the combination of rampant optimism- producers believing that their beloved movies are a quarter of the way from how good they actually are to perfection- along with a faith in moviegoers' rationality, is another way to explain the distributors' reluctance to cold-open movies.

\section{Conclusion}

In games where information about a single dimension of product quality is known to be good or bad news, and may be strategically disclosed or withheld at no cost, the only equilibrium involves the information receiver believing all withheld information conveys the worst possible news. Then the information sender should always reveal all information (except the worst).

However, this equilibrium reasoning requires many steps of iterated strategic thinking. Numerous laboratory experiments have shown in a variety of games that either noisy responses or a small number of steps of strategic thinking tends to explain data well, as parameterized by cursed equilibrium, and cognitive hierarchy $(\mathrm{CH})$ approaches with stochastic better-response. These models explain both experimental results that are far from equilibrium and other results that are surprisingly close to equilibrium, even in one-shot games (e.g., Goeree and Holt, 2001; Camerer et al., 2004).

This paper is the first to apply both parametrized behavioral models to a naturally occurring field phenomenon, an example of "structural behavioral economics." Field applications like these 
are important in showing whether principles of limited rationality that were inspired and calibrated by experimental data can also explain some basic facts in larger-scale field settings (see DellaVigna, 2007, for many examples).

We study a market in which information senders (movie distributors) are strategically withholding information (the quality of their movie) from information receivers (moviegoers), by not showing movies to critics in time for reviews to be published before opening weekends. Contrary to the simple Bayesian-Nash equilibrium, there is a "box office premium"-movies that have been cold opened earn more than other pre-screened movies with similar characteristics. Importantly, there is no such premium in foreign or video rental markets, where movies are released after the initial US release (so that reviews are widely available). The disappearance of the premium in rental and overseas markets is consistent with the hypothesis that the premium is due to some moviegoers failing to realize that no advance review is a bad signal about quality. The fact that moviegoer ratings (from imdb) are lower for these movies also suggests moviegoers' overestimated expected quality.

The cursed equilibrium model has difficulty explaining the box office premium (unless the moviegoers' curse and distributors' perceptions are different). Both restricted models perform poorly because moviegoers should correctly anticipate that cold opened movies are of low quality, which is inconsistent with the cold opening box office premium. The $\mathrm{CH}$ model with a low number of thinking steps $\tau_{m}$ to represent moviegoer naïveté, and a high $\tau_{d}$ to represent distributor over-sophistication can represent the mismatch of moviegoer perceptions and the reluctance (given expected moviegoer perceptions) of distributors to cold open.

The mismatch of parameter values for moviegoers and distributors suggest that either movie- 


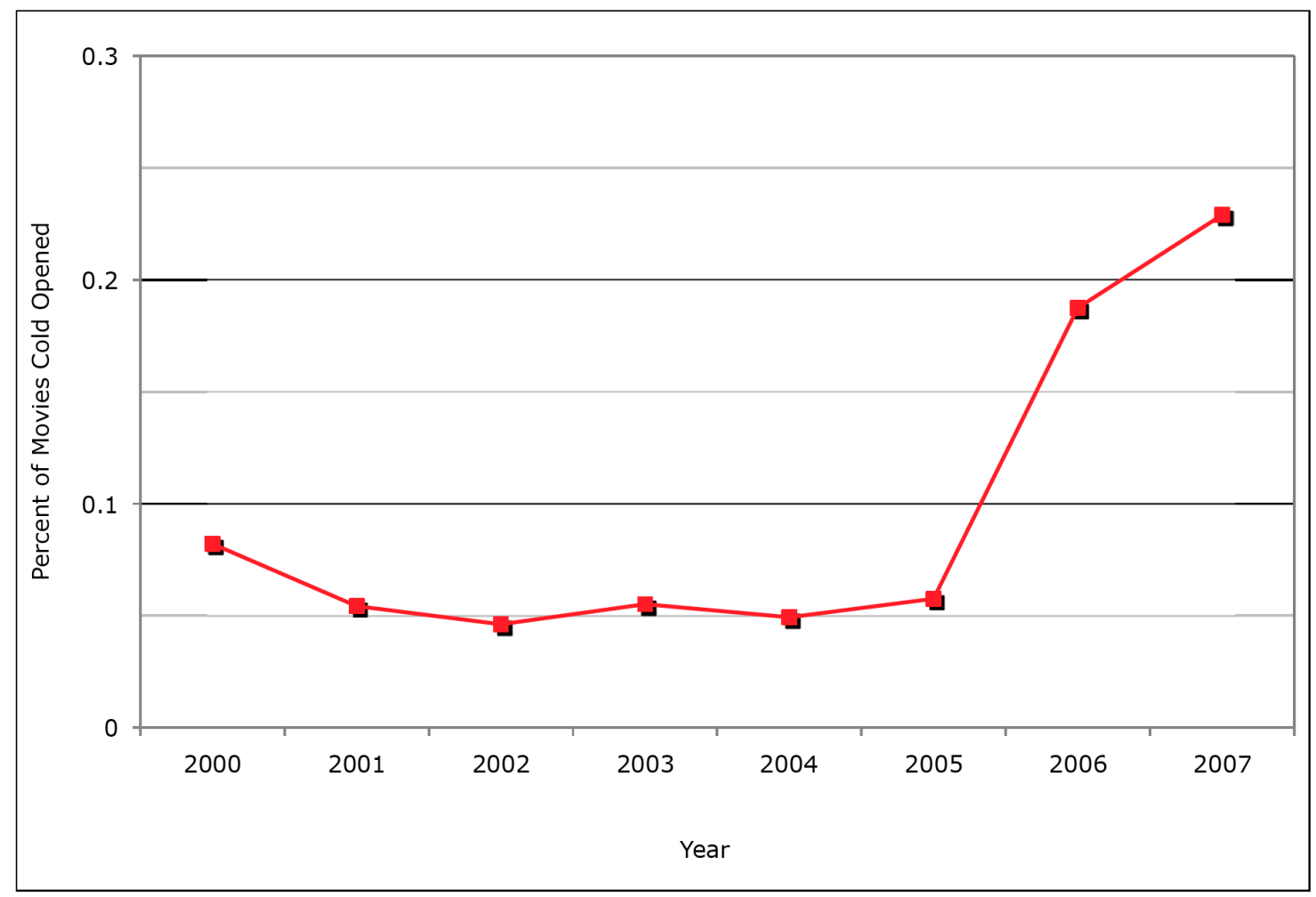

Figure 2: Percent of widely-released movies cold opened by year, 2000-2007

goers should learn over time that cold opened movies are bad, ${ }^{46}$ or distributors should learn to cold open more movies.

The time trend is consistent with the hypothesis that distributors are learning, because the number of cold opening decisions increase across the years in the sample (Figure 2). ${ }^{47}$ The models

\footnotetext{
${ }^{46} \mathrm{~A}$ natural question is how fast consumers will eventually learn that cold opened movies have low quality. Economic intuition and experiments on lemons (e.g. Lynch et al., 2001) suggest consumers will ultimately infer that goods whose quality is not disclosed have low quality. However, movie audiences contain overlapping generations, so that the relevant time frame for learning is the first few years in which teenagers go to the movies. In this time they may only learn, with noise, from a few movies that they hear little about and are disappointed by. So it is conceivable that there is a learning process but it is slow enough within a generation, and does not spill over across generations, to permit the box office premium that we see in the data.

${ }^{47}$ Through 2000-2005 distributors cold opened around 5-8\% of widely released movies. In 2006 and 2007 distrib-
} 
in this paper suggest that distributors should have cold opened more movies as a best-response to limited strategic thinking by moviegoers. However, this speculation is severely limited by the fact that over the time period we study there are substantial changes in movie economics (a shift from live box office to DVD sales and rental) and information about movie quality (which leaks out in advance more nowadays due to internet sites and blogs).

While the industry studied here, major movie distributors, is quite unique, the main parts of the industry - products of unknown quality and critical review-are found in other industries. For example, another market in which critical valuations are consumed by potential buyers is markets for expensive artworks. Mei and Moses (2005) find that estimates of selling prices, released by auction houses, are upward-biased estimates of later prices, but that investors seem to respond to these prices, as if they do not fully discount the auctioneers' incentives to inflate estimates. Our approach could be utilized to determine the sophistication of these buyers and auctioneers. The applications of this approach are much wider when one considers the similarity between cold opening and the well-studied economic problem of selective disclosure.

Since this setting features producers choosing how much information about a dimension of product quality that consumers value to disclose, it is similar to many other industries that feature selective disclosure. In relation to this literature, our results suggest that some consumers do not perfectly infer low quality from non-disclosure (i.e., from cold opening). Furthermore, the fact that IMBD ratings are about $10 \%$ lower for movies that are cold opened suggests that consumers make mistakes which they regret. However, these mistakes are small (based on the rating measures) and distributors do disclose information (through reviews) about more than $90 \%$ of the movies, so this utors cold opened 19\% (30/160) and 23\% (30/131). 
is a market in which voluntary disclosure is certainly working reasonably well.

Our results are similar to three other sharp field studies of consumer quality disclosure (Mathios, 2000; Jin and Leslie, 2003; Jin, 2005). All three studies are inconsistent with the strong hypothesis that customer strategic thinking leads to complete voluntary disclosure, so that mandatory disclosure will have no effect. Mathios (2000) studied nutrition labeling of salad dressing. Most low-fat dressings (less than 9 grams of fat per serving) were voluntarily labelled for fat content before mandatory disclosure, while only $15 \%$ of high-fat dressings were labelled. After mandatory disclosure, the share of the high-fat dressings fell by about $20 \%$. This effect is consistent with the hypothesis that some consumers did not infer that non-labeling implied high fat content, and the mandatory disclosure provided information they had not inferred (but cared about). Jin and Leslie (2003) studied the effects of a shift from voluntary to mandatory posting of standardized healthrating cards in Los Angeles restaurants. They find that mandatory disclosure increases hygiene scores by $5.3 \%$, which is about half a standard deviation of the distribution, and which is modestly significantly higher than under voluntary disclosure. ${ }^{48}$ Jin (2005) shows that HMOs do not voluntarily disclose quality (via NCQA accreditation) in markets that are the least competitive. She also finds that HMOs which voluntarily disclose tend to serve areas with large employers, which suggests that HMOs are responding differently when they have more sophisticated customers (because big firms tend to have more savvy benefits managers) than when they have less sophisticated

\footnotetext{
${ }^{48}$ Their test probably understates the effects of a shift from voluntary to mandatory disclosure because some of the voluntary-disclosure cities were expected to adopt mandatory disclosure in the near future. Restaurants might have begun complying early during the last parts of the voluntary regime, and earlier than they would have if they did not expect a shift to mandatory disclosure. Since their test understates the change from voluntary to mandatory disclosure, it therefore overstates the degree of consumer rationality.
} 
consumers.

Note, however, that our paper was not designed to pass judgment on the detailed concerns in regulatory debates about disclosure. We simply note that the limits that we infer from consumer (moviegoer) behavior on strategic thinking are comparable to conclusions drawn from the other empirical studies that are more sharply focussed on effects of disclosure changes or choices.

Finally, we note again that there are many markets and political situations with asymmetric information in which the failure to reveal information that could be revealed should be informative, if the receiver makes the proper strategic inference, and yet information is often unrevealed. Our approach could be applied to these situations. 


\section{References}

Barro, Robert J. and Paul M. Romer, "Ski-Lift Pricing, with Applications to Labor and Other Markets," American Economic Review, 1987, 77 (5), 875-890.

Borjas, George J., "Self-Selection and the Earnings of Immigrants," American Economic Review, 1987, 77 (4), 531-553.

Brown, Jennifer, Tanjim Hossain, and John Morgan, "Shrouded Attributes and Information Suppression: Evidence from the Field," Haas School of Business, 2007.

Brunnermeier, Markus K. and Jonathan A. Parker, "Optimal Expectations," American Economic Review, 2005, 95 (4), 1092-1118.

Camerer, Colin and Dan Lovallo, "Overconfidence and Excess Entry: An Experimental Approach," American Economic Review, 1999, 89 (1), 306-318.

Camerer, Colin F., Teck-Hua Ho, and Juin-Kuan Chong, "A Cognitive Hierarchy Model of Games," Quarterly Journal of Economics, 2004, 119 (3), 861-898.

Chen, Hsiao-Chi, James W. Friedman, and Jacques-Francois Thisse, "Boundedly Rational Nash Equilibrium: A Probabilistic Choice Approach,” Games and Economic Behavior, 1997, $18(1), 32-54$.

Conlin, Michael, Stacy Dickert-Conlin, and Gabrielle Chapman, "Voluntary Disclosure and the Strategic Behavior of Colleges,” Michigan State University, 2008.

Crawford, Vincent P., "Lying for Strategic Advantage: Rational and Boundedly Rational Misrepresentation of Intentions," American Economic Review, 2003, 93 (1), 133-149. 
_ and Nagore Iriberri, "Fatal Attraction: Salience, Naivete, and Sophistication in Experimental “Hide-and-Seek" Games," American Economic Review, 2007, 97 (5), 1731-1750.

_ and _, "Level-k Auctions: Can a Nonequilibrium Model of Strategic Thinking Explain the Winner's Curse and Overbidding in Private-Value Auctions?" Econometrica, 2007, 75 (6), $1721-1770$.

De Vany, Arthur and W. David Walls, "Bose-Einstein Dynamics and Adaptive Contracting in the Motion Picture Industry,” Economic Journal, 1996, 106 (439), 1493-1514.

Dye, Ronald A., "Disclosure of Nonproprietary Information," Journal of Accounting Research, 1985, $23(1), 123-145$.

_ and Sri S. Sridhar, "Industry-Wide Disclosure Dynamics," Journal of Accounting Research, 1995, $33(1), 157-174$.

Eliashberg, Jehoshua and Steven M. Shugan, "Film Critics: Influencers or Predictors?” Journal of Marketing, 1997, 61 (1), 68-78.

Eyster, Erik and Matthew Rabin, “Cursed Equilibrium,” Econometrica, 2005, 73 (5), 16231672.

Farrell, Joseph, "Voluntary Disclosure: Robustness of the Unraveling Result, and Comments on Its Importance," in Ronald E. Grieson, ed., Antitrust and Regulation, Lexington, MA: Lexington Books, 1986. 
Fishman, Michael J. and Kathleen M. Hagerty, "Mandatory Versus Voluntary Disclosure in Markets with Informed and Uninformed Customers," Journal of Law, Economics and Organization, 2003, 19 (1), 45-63.

Forsythe, Robert, R. Mark Isaac, and Thomas R. Palfrey, "Theories and Tests of "Blind Bidding" in Sealed-Bid Auctions," The RAND Journal of Economics, 1989, 20 (2), 214-238.

Germain, David, “Studios Shutting out Movie Critics,” Associated Press Archive, (April 4, 2006).

Goeree, Jacob K. and Charles A. Holt, “Ten Little Treasures of Game Theory and Ten Intuitive Contradictions," American Economic Review, 2001, 91 (5), 1402-1422.

Goldfarb, Avi and Botao Yang, “Are All Managers Created Equal?”, SSRN, 2007.

Grossman, Sanford Jay, “The Informational Role of Warranties and Private Disclosure About Product Quality," Journal of Law and Economics, 1981, 24, 461-83.

Hitsch, Günter J., Ali Hortaçsu, and Dan Ariely, "What Makes You Click?-Mate Preferences and Matching Outcomes in Online Dating," MIT Sloan School of Management, February 2006.

Jehiel, Philippe, “Analogy-Based Expectation Equilibrium,” Journal of Economic Theory, 2005, $123(2), 81-104$.

_ and Frèdèric Koessler, "Revisiting Games of Incomplete Information with Analogy-Based Expectations," Games and Economic Behavior, 2008, 62 (2), 533-557.

Jin, Ginger Zhe, "Competition and Disclosure Incentives: An Empirical Study of Hmos," The RAND Journal of Economics, 2005, 36 (1), 93-112. 
_ and Phillip Leslie, "The Effect of Information on Product Quality: Evidence from Restaurant Hygiene Grade Cards," Quarterly Journal of Economics, 2003, 118 (2), 409-451.

Jovanovic, Boyan, “Truthful Disclosure of Information,” Bell Journal of Economics, 1982, 13 (1), $36-44$.

Jung, Woon-Oh and Young K. Kwon, "Disclosure When the Market Is Unsure of Information Endowment of Managers," Journal of Accounting Research, 1988, 26 (1), 146-153.

Litwak, Mark, Reel Power: The Struggle for Influence and Success in the New Hollywood, New York: William Morrow and Co., Inc., 1986.

Luce, R. Duncan and Howard Raiffa, Games and Decisions, New York: Wiley, 1957.

Lynch, Michael, Ross Miller, Charles R. Plott, and Russell Porter, "Product Quality, Informational Efficiency, and Regulations in Experimental Markets," in Charles R. Plott, ed., Collected Papers on the Experimental Foundations of Economics and Political Science, Economists of the Twentieth Century, Cheltenham, UK ; Northampton, MA USA: Edward Elgar, 2001.

Malkiel, Burton G. and Atanu Saha, "Hedge Funds: Risk and Return," Financial Analysts Journal, 2005, 61 (6), 80-88.

Mathios, Alan D., "The Impact of Mandatory Disclosure Laws on Product Choices: An Analysis of the Salad Dressing Market," Journal of Law and Economics, 2000, 43 (2), 651-677.

Matthews, Steven and Andrew Postlewaite, "Quality Testing and Disclosure," The RAND Journal of Economics, 1985, 16 (3), 328-340. 
Mayraz, Guy, "Priors and Desires: A Model of Payout-Dependent Beliefs," London School of Economics, 2008.

McFadden, Daniel, “Conditional Logit Analysis of Qualitative Choice Behavior,” in Paul Zarembka, ed., Frontiers and Econometrics, New York: Academic Press, 1974.

McKelvey, Richard D. and Thomas R. Palfrey, "Quantal Response Equilibria for Normal Form Games," Games and Economic Behavior, 1995, 10 (1), 6-38.

_ and _, "Quantal Response Equilibria for Extensive Form Games," Experimental Economics, 1998, $1(1), 9-41$.

Mei, Jianping and Michael Moses, "Vested Interest and Biased Price Estimates: Evidence from an Auction Market," The Journal of Finance, 2005, 60 (5), 2409-2435.

Milgrom, Paul R., “Good News and Bad News: Representation Theorems and Applications,” Bell Journal of Economics, 1981, 12 (2), 380-391.

Nagel, Rosemarie, "Unraveling in Guessing Games: An Experimental Study," American Economic Review, 1995, 85 (5), 1313-1326.

Orbach, Barak Y. and Liran Einav, "Uniform Prices for Differentiated Goods: The Case of the Movie-Theater Industry," International Review of Law and Economics, 2007, 27 (2), 129-153.

Ostling, Robert, Joseph Tao yi Wang, Eileen Chou, and Colin F. Camerer, "Field and Lab Convergence in Poisson Lupi Games," California Institute of Technology, 2007. 
Reinstein, David A. and Christopher M. Snyder, "The Influence of Expert Reviews on Consumer Demand for Experience Goods: A Case Study of Movie Critics," Journal of Industrial Economics, 2005, 53 (1), 27-51.

Shavell, Steven, “Acquisition and Disclosure of Information Prior to Sale," The RAND Journal of Economics, 1994, 25 (1), 20-36.

Shin, Hyun Song, "News Management and the Value of Firms," The RAND Journal of Economics, 1994, 25 (1), 58-71.

_ , "Disclosures and Asset Returns," Econometrica, 2003, 71 (1), 105-133.

Silverman, Bernard W., Density Estimation for Statistics and Data Analysis Monographs on Statistics and Applied Probability, New York: Chapman and Hall, 1986.

Simmons, Jacqueline, “A 'Thumbs up' Pulls in the Audience,” Wall Street Journal, (March 25, 1994).

Stahl, Dale O. and Paul W. Wilson, "On Players' Models of Other Players: Theory and Experimental Evidence," Games and Economic Behavior, 1995, 10 (1), 218-254.

Verrecchia, Robert E., "Essays on Disclosure," Journal of Accounting and Economics, 2001, 32 (1-3), 97-180.

Viscusi, W. Kip, "A Note on "Lemons" Markets with Quality Certification," Bell Journal of Economics, 1978, 9 (1), 277-279.

Vogel, Howard L., Entertainment Industry Economics, Cambridge: Cambridge University Press, 2007. 
Wang, Joseph T., “Is Last Minute Bidding Bad?”, California Institute of Technology, 2006. 


\section{Appendices: Not for Publication}

\section{A Description of Variables}

To determine if a movie was cold opened $\left(c_{j}=1\right)$ we examined the dates on three or four major news publications (the Los Angeles Times, New York Times, San Francisco Chronicle, and New York Post). If the dates of reviews in any of these publications were later than the release date we examined the reasoning behind the late reviews. A movie was classified a "cold open" if at least one source stated the movie was not screened for critics before release (in most cases, none of the available sources had advance reviews).

Weekend and total US box office data were obtained from a FilmSource database (Nielsen EDI, www. filmsource.com). The FilmSource database also included the number of theaters that showed a movie during its first weekend, the number of days in the opening weekend, and if the movie was released before Friday (generally only for anticipated blockbusters). FilmSource also gave a description of the genre of the movie, its MPAA rating ( $\mathrm{G}, \mathrm{PG}, \mathrm{PG}-13, \mathrm{R})$, and whether the movie was adapted from previous source material.

Production budget information came from imdb.com for most movies, and from boxofficemojo.com or the-numbers.com for those missing from imdb.com. Budget data were available for 856 of the 890 movies, including 59 or the 62 cold openings (95\%). Of this set, 832 movies also had the first day's box office data available on imdb.com including 59 of the 62 cold openings.

The imdb.com database was used to determine the star power rating of each movie's stars. Each week imdb.com determined this value by ranking the number of searches done on the imdb.com site for every person affiliated with movies. The most searched star would have value 1 . Since 
there are over one million stars on imdb.com, we took the natural logarithm of the star ranking to reduce effect of unknown stars with very high numbers. We averaged the logged star ranking for the top two stars for each movie during its opening week.

Three other variables, competition (the average production budget of other movies released on the same opening weekend), the summer dummy variable (whether the movie was released in June, July and August), and the year of release variable $(2000=-3,2001=-2,2002=-1,2003=0,2004=1$, $2005=2,2006=3$ ) were calculated from the previous data. ${ }^{49}$

\section{B Supplemental Tables and Figures}

Table A.1 shows the regressions done on logged opening day box office in the full and lean regressions. Table A.2 shows regressions done on logged post-opening-weekend box office in the full and lean regressions including logged opening weekend box office as a regressor. Table A.3 shows the correlations between the regressors in the full regressions done on box office. Table A.4 shows values after each iteration in estimating the cursed parameters with quantal response $(\mathrm{QR})$. Table A.5 shows values after each iteration in estimating the $\mathrm{CH}$ parameters with $\mathrm{QR}$.

Figure A.1 shows the predicted probabilities of cold opening by critic quality and actual decision. About half the movies cold-opened (squares) have high predicted probabilities and half have low probabilities. There is a clear relation between quality and the predicted probability of cold opening. The model is on the right track but the correlation is far from perfect. Figure A.2 shows the expected quality of each movie given it was cold opened vs. the actual quality. Since moviegoers correctly infer expectations in the QRE, about half the cold opened movies have quality less

\footnotetext{
${ }^{49}$ The regressions had similar results when dummy variables for year were used instead of one year variable.
} 


\begin{tabular}{|c|c|c|}
\hline variable/regression & $\log 1$ st day & $\log 1$ st day \\
\hline \multirow{2}{*}{ cold } & $0.119^{*}$ & $0.153^{* *}$ \\
\hline & $(0.083)$ & $(0.086)$ \\
\hline \multirow{2}{*}{ crit } & $0.012 * * *$ & $0.010 * * *$ \\
\hline & $(0.001)$ & $(0.001)$ \\
\hline \multirow{2}{*}{ thtr } & $0.875^{* * *}$ & $0.822 * * *$ \\
\hline & $(0.037)$ & $(0.035)$ \\
\hline \multirow{2}{*}{ bud } & $0.002 * * *$ & $0.001 *$ \\
\hline & $(0.001)$ & $(0.001)$ \\
\hline \multirow{2}{*}{ comp } & $0.015 * *$ & 0.001 \\
\hline & $(0.001)$ & $(0.001)$ \\
\hline \multirow{2}{*}{ star } & $-0.026^{*}$ & $-0.066 * * *$ \\
\hline & $(0.015)$ & $(0.014)$ \\
\hline \multirow{2}{*}{ sum } & $0.101^{* *}$ & \multirow{2}{*}{-} \\
\hline & $(0.046)$ & \\
\hline \multirow{2}{*}{ sq/adpt } & $0.139 * * *$ & $0.097 * *$ \\
\hline & $(0.043)$ & $(0.044)$ \\
\hline \multirow{2}{*}{ beffri } & 0.000 & \multirow[b]{2}{*}{ - } \\
\hline & $(0.000)$ & \\
\hline \multirow{2}{*}{ wkdlen } & -0.001 & \multirow{2}{*}{-} \\
\hline & $(0.059)$ & \\
\hline \multirow{2}{*}{ beffor } & 0.000 & \multirow{2}{*}{ - } \\
\hline & $(0.000)$ & \\
\hline \multirow{2}{*}{$\mathrm{act} / \mathrm{adv}$} & 0.082 & \multirow{2}{*}{ - } \\
\hline & $(0.073)$ & \\
\hline \multirow{2}{*}{ ani } & $-0.264 * *$ & \multirow{2}{*}{ - } \\
\hline & $(0.120)$ & \\
\hline \multirow{2}{*}{ com } & 0.021 & \multirow{2}{*}{ - } \\
\hline & $(0.061)$ & \\
\hline \multirow{2}{*}{ doc } & 0.493 & \multirow[b]{2}{*}{ - } \\
\hline & $(0.334)$ & \\
\hline & 0.131 & - \\
\hline fant/sc1 & $(0.096)$ & - \\
\hline & 0.035 & \\
\hline susp/nor & $(0.074)$ & - \\
\hline & $-0.041 * * *$ & $-0.037 * * *$ \\
\hline year & 0.011 & $(0.011)$ \\
\hline & -0.105 & \\
\hline pg & $(0.130)$ & - \\
\hline no13 & $0.376^{* * * *}$ & 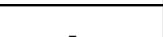 \\
\hline pg15 & $(0.127)$ & - \\
\hline & $0.384^{* * *}$ & - \\
\hline $\mathrm{r}$ & $(0.130)$ & - \\
\hline const & $-1.843 * * *$ & $-1.10 * * *$ \\
\hline const & $(0.196)$ & $(0.134)$ \\
\hline R-squared & 0.670 & 0.622 \\
\hline $\mathrm{N}$ & 833 & 833 \\
\hline degrees of freedom & 21 & 8 \\
\hline$* \mathrm{p}<0.1, *$ & $\mathrm{p}<0.05, * * * \mathrm{p}<$ & .01 \\
\hline
\end{tabular}

Table A.1: Regressions of log opening day revenues (in millions)

\begin{tabular}{|c|c|c|}
\hline variableไregression & $\begin{array}{l}\text { Tog post- } \\
\text { opening } \\
\text { weekend }\end{array}$ & $\begin{array}{l}\text { Tog post- } \\
\text { opening } \\
\text { weekend }\end{array}$ \\
\hline \multirow{2}{*}{ log rwkd } & $1.210^{* * *}$ & $1.177 * * *$ \\
\hline & $(0.024)$ & $(0.026)$ \\
\hline \multirow{2}{*}{ cold } & -0.035 & $-0.091^{*}$ \\
\hline & $(0.051)$ & $(0.054)$ \\
\hline \multirow{2}{*}{ crit } & $0.009 * * *$ & $0.009 * * *$ \\
\hline & $(0.001)$ & $(0.001)$ \\
\hline \multirow{2}{*}{ thtr } & $-0.134 * * *$ & $-0.076^{* *}$ \\
\hline & $(0.030)$ & $(0.030)$ \\
\hline \multirow{2}{*}{ bud } & $1.21 * * *$ & 0.000 \\
\hline & $(0.001)$ & $(0.001)$ \\
\hline \multirow{2}{*}{ comp } & $0.001 * * *$ & $0.002 * * *$ \\
\hline & $(0.000)$ & $(0.000)$ \\
\hline \multirow{2}{*}{ star } & $-0.016^{*}$ & -0.001 \\
\hline & $(0.009)$ & $(0.009)$ \\
\hline \multirow{2}{*}{ sum } & 0.035 & \multirow{2}{*}{-} \\
\hline & $(0.028)$ & \\
\hline \multirow{2}{*}{ sq/adpt } & -0.020 & -0.013 \\
\hline & $(0.026)$ & $(0.028)$ \\
\hline \multirow{2}{*}{ beffri } & $0.087 * * *$ & \multirow{2}{*}{ - } \\
\hline & $(0.019)$ & \\
\hline \multirow{2}{*}{ wkdlen } & $-0.121 * * *$ & \multirow{2}{*}{ - } \\
\hline & $(0.036)$ & \\
\hline \multirow{2}{*}{ beffor } & 0.000 & \multirow{2}{*}{ - } \\
\hline & $(0.000)$ & \\
\hline \multirow{2}{*}{ act/adv } & $-0.166 * * *$ & \multirow{2}{*}{-} \\
\hline & $(0.044)$ & \\
\hline \multirow{2}{*}{ ani } & $-0.238 * * *$ & \multirow{2}{*}{-} \\
\hline & $(0.073)$ & \\
\hline \multirow{2}{*}{ com } & 0.001 & \multirow{2}{*}{-} \\
\hline & $(0.036)$ & \\
\hline & -0.197 & \\
\hline doc & $(0.206)$ & - \\
\hline & $-0.329 * * *$ & \\
\hline tant/sc1 & $(0.059)$ & - \\
\hline susn/hor & -0.048 & 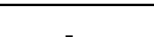 \\
\hline susp/nor & $(0.044)$ & - \\
\hline & $-0.042 * * *$ & $-0.041 * * *$ \\
\hline year & $(0.007)$ & $(0.007)$ \\
\hline & $-0.201 * * *$ & \\
\hline pg & $(0.074)$ & - \\
\hline $\operatorname{pg} 13$ & $-0.427 * * *$ & \\
\hline pg13 & $(0.077)$ & - \\
\hline & $-0.52 * * *$ & \\
\hline $\mathrm{r}$ & $(0.079)$ & - \\
\hline & $0.556^{* * *}$ & -0.060 \\
\hline const & $(0.119)$ & $(0.026)$ \\
\hline R-squared & 0.916 & 0.899 \\
\hline $\mathrm{N}$ & 856 & 833 \\
\hline degrees of freedom & 21 & 8 \\
\hline$* \mathrm{p}<0.1, *$ & $0<0.05, * * * \mathrm{p}<$ & \\
\hline
\end{tabular}

Table A.2: Regressions of log box office revenues after first weekend (in millions) 


\begin{tabular}{|c|c|c|c|c|c|c|c|c|c|c|c|c|c|c|c|c|c|c|c|c|c|}
\hline & Cold & crit & $\begin{array}{c}\text { theater } \\
\mathrm{s}\end{array}$ & rBud & Actor 1 & Actor 2 & $\mathrm{Hol}$ & $\begin{array}{l}\text { adapt } \\
\text { or seq }\end{array}$ & BefFri & $\begin{array}{l}\text { Wkd } \\
\text { Len }\end{array}$ & $\begin{array}{c}\text { Before } \\
\text { Foreign } \\
\end{array}$ & $\begin{array}{l}\text { Act/ } \\
\text { Adv }\end{array}$ & $\begin{array}{c}\text { Ani- } \\
\text { mated }\end{array}$ & $\begin{array}{l}\text { Com- } \\
\text { edy }\end{array}$ & $\begin{array}{c}\text { Docu- } \\
\text { mentary }\end{array}$ & $\begin{array}{c}\text { Fant/ } \\
\text { Sci }\end{array}$ & $\begin{array}{l}\text { Susp/ } \\
\text { Horr }\end{array}$ & YEAR & $P G$ & PG-13 & $\mathrm{R}$ \\
\hline Cold & 1.00 & -0.33 & -0.15 & -0.17 & -0.06 & 0.12 & -0.05 & -0.08 & -0.03 & 0.01 & 0.01 & -0.06 & -0.05 & -0.01 & -0.02 & 0.00 & 0.20 & 0.07 & -0.11 & 0.06 & 0.03 \\
\hline crit & -0.33 & 1.00 & 0.16 & 0.28 & 0.10 & -0.11 & 0.04 & 0.13 & 0.12 & 0.00 & 0.04 & 0.06 & 0.16 & -0.18 & 0.04 & 0.08 & -0.12 & 0.12 & 0.04 & -0.06 & -0.01 \\
\hline theaters & -0.15 & 0.16 & 1.00 & 0.58 & 0.07 & -0.38 & 0.11 & 0.26 & 0.07 & 0.02 & -0.12 & 0.22 & 0.16 & -0.11 & -0.10 & 0.19 & -0.03 & 0.15 & 0.17 & 0.10 & -0.28 \\
\hline rBud & -0.17 & 0.28 & 0.58 & 1.00 & 0.12 & -0.40 & 0.14 & 0.24 & 0.19 & 0.04 & -0.08 & 0.32 & 0.09 & -0.26 & -0.07 & 0.28 & -0.16 & 0.01 & 0.05 & 0.11 & -0.16 \\
\hline Actor 1 & -0.06 & 0.10 & 0.07 & 0.12 & 1.00 & -0.05 & 0.15 & 0.05 & 0.11 & 0.05 & 0.01 & 0.01 & 0.06 & 0.06 & -0.01 & 0.00 & -0.08 & -0.01 & 0.10 & 0.02 & -0.11 \\
\hline Actor 2 & 0.12 & -0.11 & -0.38 & -0.40 & -0.05 & 1.00 & -0.06 & -0.09 & -0.05 & 0.01 & 0.10 & -0.15 & 0.25 & 0.03 & 0.17 & -0.11 & 0.00 & 0.02 & 0.17 & -0.17 & -0.03 \\
\hline Hol & -0.05 & 0.04 & 0.11 & 0.14 & 0.15 & -0.06 & 1.00 & 0.04 & 0.08 & -0.11 & 0.01 & 0.06 & 0.00 & 0.02 & 0.06 & 0.06 & -0.03 & -0.02 & 0.04 & 0.06 & -0.10 \\
\hline adapt or seq & -0.08 & 0.13 & 0.26 & 0.24 & 0.05 & -0.09 & 0.04 & 1.00 & 0.13 & 0.02 & -0.05 & 0.11 & 0.05 & -0.16 & -0.05 & 0.14 & 0.02 & 0.10 & 0.09 & -0.04 & -0.05 \\
\hline BefFri & -0.03 & 0.12 & 0.07 & 0.19 & 0.11 & -0.05 & 0.08 & 0.13 & 1.00 & 0.09 & -0.05 & 0.01 & 0.05 & -0.02 & 0.04 & 0.07 & -0.09 & -0.03 & 0.02 & -0.02 & -0.02 \\
\hline WkdLen & 0.01 & 0.00 & 0.02 & 0.04 & 0.05 & 0.01 & -0.11 & 0.02 & 0.09 & 1.00 & -0.03 & -0.01 & 0.02 & -0.02 & -0.02 & 0.03 & -0.05 & -0.03 & 0.01 & 0.04 & -0.06 \\
\hline ForBef & 0.01 & 0.04 & -0.12 & -0.08 & 0.01 & 0.10 & 0.01 & -0.05 & -0.05 & -0.03 & 1.00 & 0.09 & -0.01 & -0.07 & -0.01 & -0.01 & 0.03 & -0.02 & -0.02 & -0.04 & 0.05 \\
\hline Act/Adv & -0.06 & 0.06 & 0.22 & 0.32 & 0.01 & -0.15 & 0.06 & 0.11 & 0.01 & -0.01 & 0.09 & 1.00 & -0.11 & -0.35 & -0.03 & -0.12 & -0.20 & 0.04 & -0.07 & 0.09 & -0.01 \\
\hline Animated & -0.05 & 0.16 & 0.16 & 0.09 & 0.06 & 0.25 & 0.00 & 0.05 & 0.05 & 0.02 & -0.01 & -0.11 & 1.00 & -0.20 & -0.01 & -0.07 & -0.11 & 0.00 & 0.24 & -0.23 & -0.18 \\
\hline Comedy & -0.01 & -0.18 & -0.11 & -0.26 & 0.06 & 0.03 & 0.02 & -0.16 & -0.02 & -0.02 & -0.07 & -0.35 & -0.20 & 1.00 & -0.05 & -0.20 & -0.34 & -0.02 & 0.05 & 0.14 & -0.16 \\
\hline Documentary & -0.02 & 0.04 & -0.10 & -0.07 & -0.01 & 0.17 & 0.06 & -0.05 & 0.04 & -0.02 & -0.01 & -0.03 & -0.01 & -0.05 & 1.00 & -0.02 & -0.03 & 0.04 & -0.03 & -0.02 & 0.04 \\
\hline Fant/Sci & 0.00 & 0.08 & 0.19 & 0.28 & 0.00 & -0.11 & 0.06 & 0.14 & 0.07 & 0.03 & -0.01 & -0.12 & -0.07 & -0.20 & -0.02 & 1.00 & -0.11 & 0.00 & 0.11 & 0.04 & -0.11 \\
\hline Susp/Horr & 0.20 & -0.12 & -0.03 & -0.16 & -0.08 & 0.00 & -0.03 & 0.02 & -0.09 & -0.05 & 0.03 & -0.20 & -0.11 & -0.34 & -0.03 & -0.11 & 1.00 & 0.04 & -0.19 & -0.10 & 0.28 \\
\hline YEAR & 0.07 & 0.12 & 0.15 & 0.01 & -0.01 & 0.02 & -0.02 & 0.10 & -0.03 & -0.03 & -0.02 & 0.04 & 0.00 & -0.02 & 0.04 & 0.00 & 0.04 & 1.00 & 0.09 & 0.02 & -0.10 \\
\hline PG & -0.11 & 0.04 & 0.17 & 0.05 & 0.10 & 0.17 & 0.04 & 0.09 & 0.02 & 0.01 & -0.02 & -0.07 & 0.24 & 0.05 & -0.03 & 0.11 & -0.19 & 0.09 & 1.00 & -0.41 & -0.30 \\
\hline PG-13 & 0.06 & -0.06 & 0.10 & 0.11 & 0.02 & -0.17 & 0.06 & -0.04 & -0.02 & 0.04 & -0.04 & 0.09 & -0.23 & 0.14 & -0.02 & 0.04 & -0.10 & 0.02 & -0.41 & 1.00 & -0.66 \\
\hline$R$ & 0.03 & -0.01 & -0.28 & -0.16 & -0.11 & -0.03 & -0.10 & -0.05 & -0.02 & -0.06 & 0.05 & -0.01 & -0.18 & -0.16 & 0.04 & -0.11 & 0.28 & -0.10 & -0.30 & -0.66 & 1.00 \\
\hline
\end{tabular}

Table A.3: Correlation between variables

than their actual critic ratings. The low value of $\lambda_{d}$ causes a wide variety of expectation values for cold opened movies between 0 and 40 .

Figure A.3 which represents the estimated probability that each movie will be cold opened, with actual cold-openings plotted in red. The implied line from the scatter plot is much clearer in Figure A.3 than in Figure A.1 for the QRE model. The cold opened movies on average have higher probabilities of being cold opened, so the model fits better. Figure A. 2 shows the estimated value of the expected quality belief moviegoers would have if each movie had been cold opened. This is almost a constant because of the relatively high $\lambda_{d}$ and lower $\tau_{m}$. Moviegoers expect few cold opening decisions to be the result of quantal response, but they mostly expect distributors to be best responding to 0 or 1 level moviegoers who do not associate quality with movies or the decision to cold open. Note that cold opened movies (red squares) tend to have expected quality above actual quality and screened movies have expected quality below actual quality. Tables A.6 and A.7 show the sum of squares and log likelihood for the various values of estimates of $\tau_{d}$ and $\left\{\tau_{d}, \lambda_{d}\right\}$, respectively. 


\begin{tabular}{|c|c|c|c|c|c|c|}
\hline variableliteration & 1st & 2nd & 3rd & 4th & 5 th & 6th \\
\hline$\lambda_{\mathrm{m}}$ & 1.285 & 1.290 & 1.282 & 1.291 & 1.288 & 1.288 \\
\hline crit & 0.017 & 0.016 & 0.015 & 0.016 & 0.016 & 0.016 \\
\hline thtr & 0.001 & 0.001 & 0.001 & 0.001 & 0.001 & 0.001 \\
\hline bud & 0.003 & 0.003 & 0.003 & 0.003 & 0.003 & 0.003 \\
\hline comp & 0.002 & 0.002 & 0.002 & 0.002 & 0.002 & 0.002 \\
\hline star & -0.041 & -0.036 & -0.037 & -0.037 & -0.037 & -0.037 \\
\hline sum & 0.057 & 0.040 & 0.035 & 0.037 & 0.036 & 0.036 \\
\hline sq/adpt & 0.101 & 0.105 & 0.101 & 0.105 & 0.102 & 0.102 \\
\hline beffri & 0.001 & 0.001 & 0.007 & 0.004 & 0.007 & 0.007 \\
\hline wkdlen & 0.101 & 0.100 & 0.097 & 0.099 & 0.098 & 0.098 \\
\hline beffor & 0.000 & 0.000 & 0.000 & 0.000 & 0.000 & 0.000 \\
\hline act/adv & -0.140 & -0.151 & -0.153 & -0.148 & -0.149 & -0.149 \\
\hline ani & -0.247 & -0.236 & -0.232 & -0.234 & -0.233 & -0.233 \\
\hline com & 0.023 & 0.022 & 0.014 & 0.022 & 0.018 & 0.018 \\
\hline doc & 0.211 & 0.193 & 0.197 & 0.196 & 0.196 & 0.196 \\
\hline fant/sci & -0.140 & -0.120 & -0.121 & -0.119 & -0.120 & -0.120 \\
\hline susp/hor & 0.001 & 0.025 & 0.042 & 0.028 & 0.037 & 0.037 \\
\hline year & -0.073 & -0.062 & -0.061 & -0.064 & -0.063 & -0.063 \\
\hline pg & -0.151 & -0.141 & -0.142 & -0.141 & -0.142 & -0.142 \\
\hline pg13 & -0.165 & -0.124 & -0.122 & -0.126 & -0.123 & -0.123 \\
\hline $\mathrm{r}$ & -0.205 & -0.164 & -0.170 & -0.166 & -0.169 & -0.169 \\
\hline R-squared & 0.683 & 0.682 & 0.678 & 0.682 & 0.681 & 0.682 \\
\hline $\mathrm{N}$ & 797 & 856 & 856 & 856 & 856 & 856 \\
\hline degrees of freedom & 20 & 20 & 20 & 20 & 20 & 20 \\
\hline$\lambda_{\mathrm{d}}$ & 1.478 & 1.356 & 1.367 & 1.350 & 1.345 & - \\
\hline$\chi$ & 0.000 & 0.000 & 0.000 & 0.000 & 0.000 & - \\
\hline log likelihood & -191.308 & -198.569 & -196.965 & -203.406 & -205.712 & - \\
\hline Mean $E_{m}(q \mid X j, 1)$ for $\lambda_{d}$ & 14.159 & 13.264 & 14.894 & 15.319 & 15.106 & - \\
\hline
\end{tabular}

Table A.4: The iterative estimation process for the cursed equilibrium model with quantal response 


\begin{tabular}{|c|c|c|c|c|c|}
\hline variableliteration & $1 \mathrm{st}$ & 2nd & $3 \mathrm{rd}$ & 4th & 5 th \\
\hline$\overline{\lambda_{\mathrm{m}}}$ & 1.285 & 1.302 & 1.302 & 1.302 & 1.302 \\
\hline crit & 0.017 & 0.017 & 0.017 & 0.017 & 0.017 \\
\hline thtr & 0.001 & 0.001 & 0.001 & 0.001 & 0.001 \\
\hline bud & 0.003 & 0.003 & 0.003 & 0.003 & 0.003 \\
\hline comp & 0.002 & 0.002 & 0.002 & 0.002 & 0.002 \\
\hline star & -0.041 & -0.039 & -0.039 & -0.039 & -0.039 \\
\hline sum & 0.057 & 0.036 & 0.037 & 0.037 & 0.037 \\
\hline sq/adpt & 0.101 & 0.107 & 0.108 & 0.108 & 0.108 \\
\hline beffri & 0.001 & 0.000 & 0.000 & 0.000 & 0.000 \\
\hline wkdlen & 0.101 & 0.095 & 0.095 & 0.095 & 0.095 \\
\hline beffor & 0.000 & 0.000 & 0.000 & 0.000 & 0.000 \\
\hline act/adv & -0.140 & -0.154 & -0.155 & -0.155 & -0.155 \\
\hline ani & -0.247 & -0.253 & -0.254 & -0.254 & -0.254 \\
\hline com & 0.023 & 0.016 & 0.016 & 0.016 & 0.016 \\
\hline doc & 0.211 & 0.226 & 0.228 & 0.228 & 0.228 \\
\hline fant/sci & -0.140 & -0.152 & -0.153 & -0.153 & -0.154 \\
\hline susp/hor & 0.001 & -0.016 & -0.018 & -0.018 & -0.018 \\
\hline year & -0.073 & -0.066 & -0.066 & -0.066 & -0.066 \\
\hline pg & -0.151 & -0.139 & -0.139 & -0.139 & -0.139 \\
\hline $\operatorname{pg} 13$ & -0.165 & -0.148 & -0.149 & -0.149 & -0.149 \\
\hline $\mathrm{r}$ & -0.205 & -0.177 & -0.177 & -0.177 & -0.177 \\
\hline R-squared & 0.683 & 0.682 & 0.674 & 0.682 & 0.682 \\
\hline $\mathrm{N}$ & 797 & 856 & 856 & 856 & 856 \\
\hline degrees of freedom & 20 & 20 & 20 & 20 & 20 \\
\hline$\lambda_{\mathrm{d}}$ & 6.816 & 7.136 & 7.090 & 7.085 & - \\
\hline$\tau_{\mathrm{d}}$ & 8.567 & 8.550 & 8.554 & 8.554 & - \\
\hline log likelihood & -166.424 & -166.226 & -166.231 & -166.232 & - \\
\hline$\tau_{\mathrm{m}}$ & 1.26 & 1.15 & 1.13 & 1.12 & - \\
\hline Mean $E_{m}(q \mid X j, 1)$ for $\tau_{m}, \lambda_{d}$ & 44.666 & 45.254 & 45.359 & 45.412 & - \\
\hline
\end{tabular}

Table A.5: The iterative estimation process for the $\mathrm{CH}$ model with quantal response 


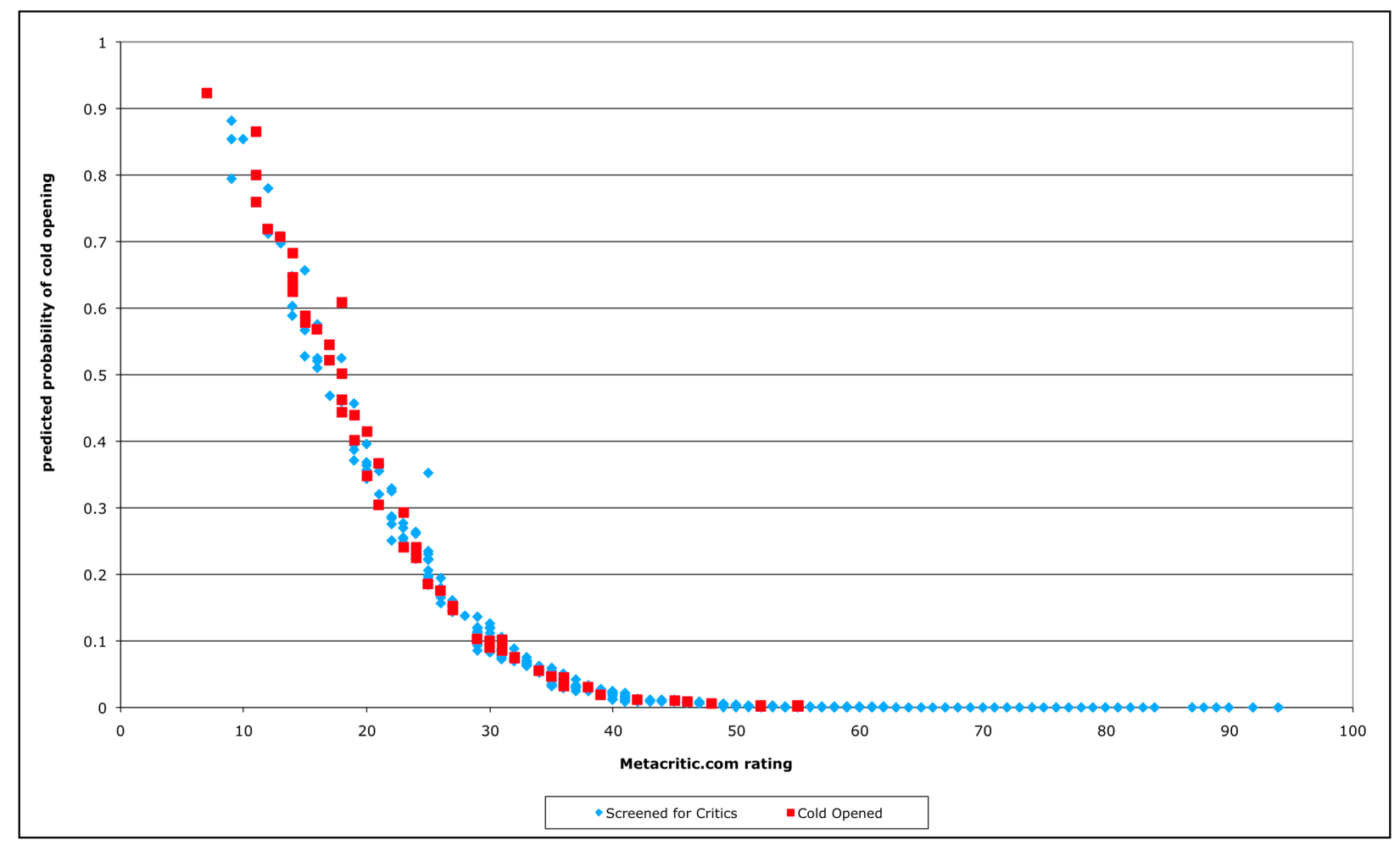

Figure A.1: Probability of movie being cold opened in QRE model by critic rating $\left(\lambda_{d}=1.345\right)$

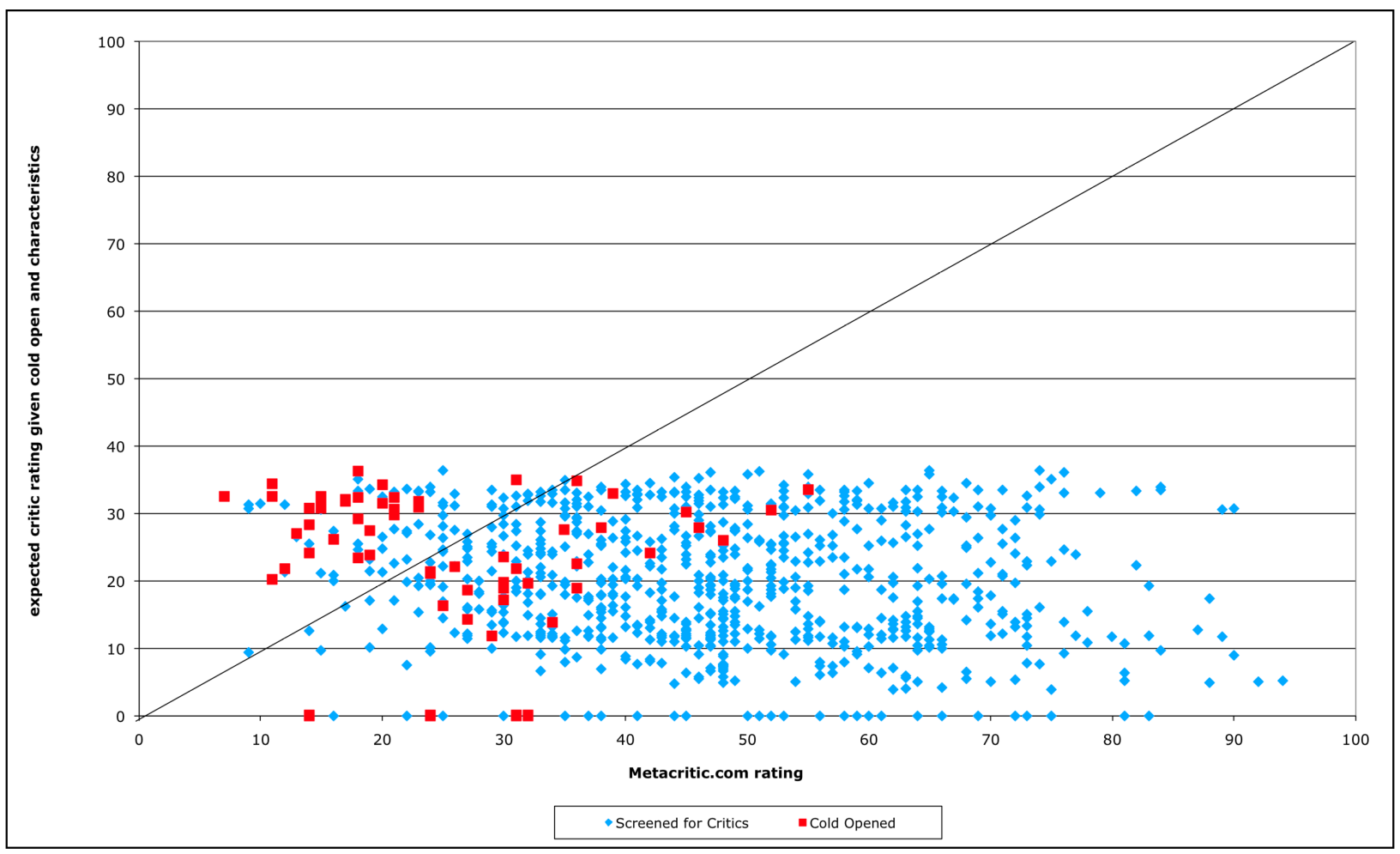

Figure A.2: Expected movie quality given it is cold opened in QRE model by critic rating $\left(\lambda_{d}=\right.$ $1.345)$ 


\begin{tabular}{|r|r|}
\hline$\tau_{\mathrm{m}}$ & (Average SSR $^{1 / 2}$ \\
\hline 0 & 5.14 \\
$1.12^{*}$ & 5.08 \\
2 & 5.08 \\
4 & 5.14 \\
6 & 5.35 \\
8 & 5.59 \\
10 & 5.81 \\
\hline
\end{tabular}

Table A.6: Average squared difference between predicted and actual weekend revenues (in \$) for all cold openings $(N=59)$ by moviegoer sophistication in $\mathrm{CH}$ model with $\mathrm{QR}\left(\lambda_{d}=7.085\right)$

\begin{tabular}{|r|rrrrrr|}
\hline$\tau_{\mathrm{d}} \backslash \boldsymbol{\lambda}_{\mathrm{d}}$ & 0 & 3 & 6 & $7.085^{*}$ & 9 \\
\hline 0 & -593.33 & -593.33 & -593.33 & -593.33 & -593.33 \\
\hline 2 & -593.33 & -783.20 & -798.29 & -800.62 & -803.45 \\
\hline 4 & -593.33 & -441.44 & -438.66 & -438.31 & -438.17 \\
6 & -593.33 & -248.56 & -230.67 & -228.38 & -226.32 \\
\hline 8 & -593.33 & -183.70 & -169.26 & -168.39 & -167.89 \\
\hline $8.567^{*}$ & -593.33 & -177.43 & -166.43 & $\mathbf{- 1 6 6 . 2 3}$ & -166.44 \\
10 & -593.33 & -173.94 & -175.62 & -177.55 & -179.92 \\
\hline
\end{tabular}

Table A.7: Log likelihood for all distributor release decisions $(N=856)$ in $\mathrm{CH}$ model with QR by distributor sophistication 


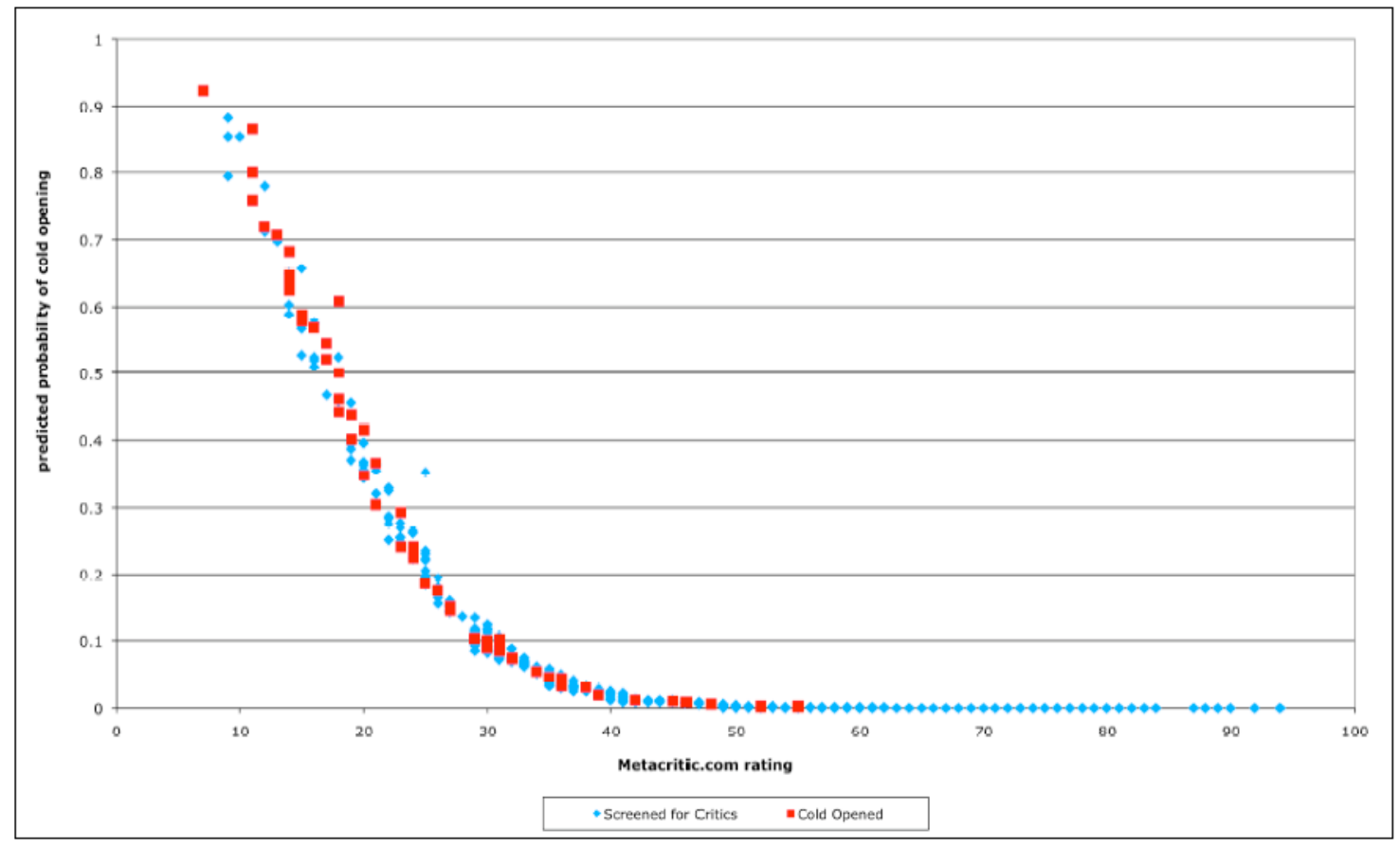

Figure A.3: Probability of movie being cold opened in $\mathrm{CH}$ model with $\mathrm{QR}$ by critic rating $(\lambda=$ $7.085, \tau_{d}=8.567$ )

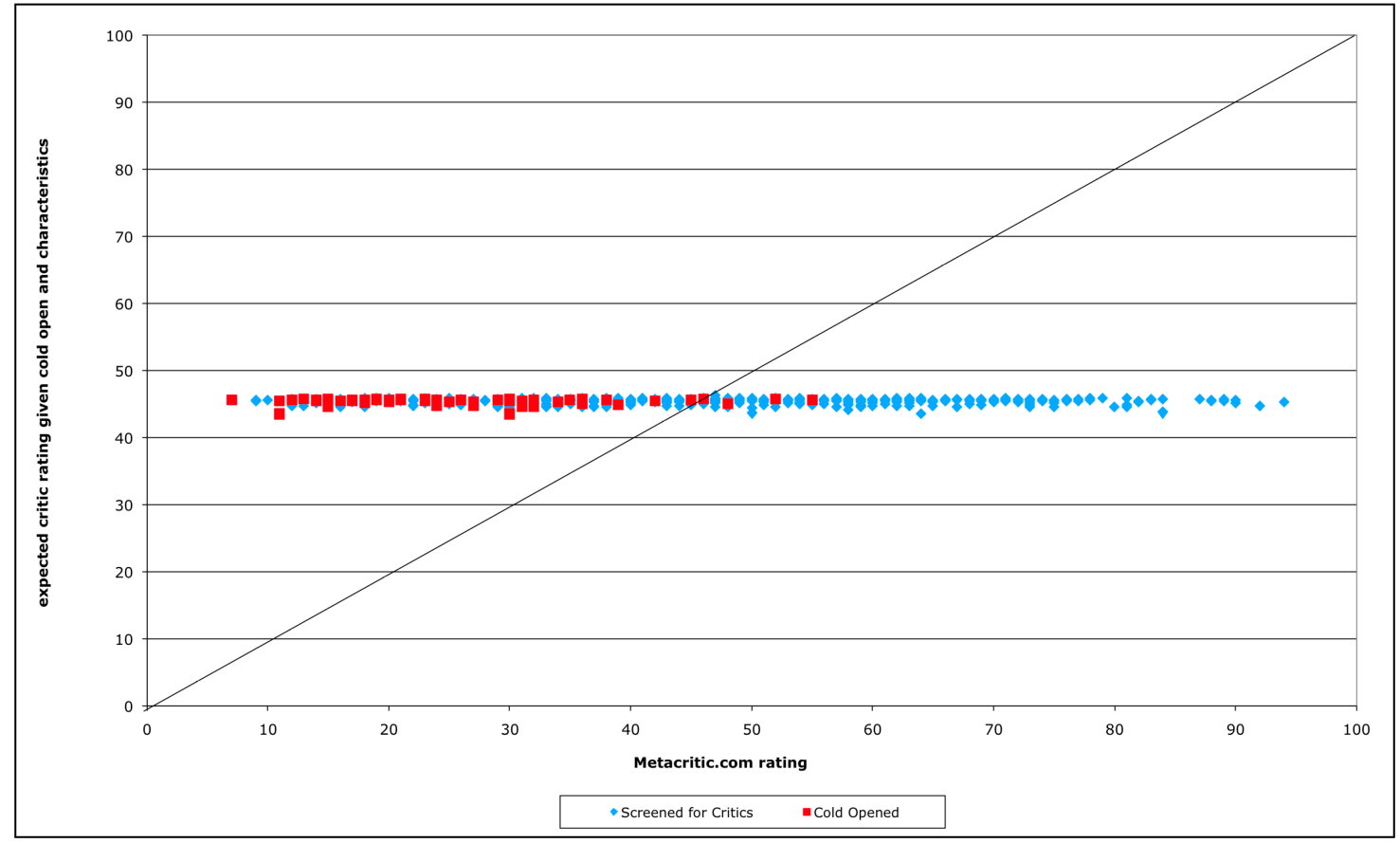

Figure A.4: Expected movie quality given it is cold opened in $\mathrm{CH}$ model with $\mathrm{QR}$ by critic rating $\left(\lambda=7.085, \tau_{d}=8.567\right)$ 


\section{Details of Iterative Estimation Procedures (QRE, Cursed,}

\section{CH)}

This section provides the general iterative procedure for obtaining estimates for the relevant parameters of the QRE, cursed and $\mathrm{CH}$ models.

1. The iteration counter begins at $i=1$.

2. The coefficients in equation 6 are estimated using a linear regression,

$$
\log \left(\frac{y_{j}}{N \hat{t}-y_{j}}\right)=\left(-\lambda_{m} \alpha\right) E_{m}\left(q_{j} \mid c_{j}, X_{j}\right)-\left(\lambda_{m} \beta\right) X_{j}-\left(\lambda_{m}\right) \hat{t}-\left(\lambda_{m}\right) \epsilon_{j}
$$

assuming $N=300 \times 10^{6}$ and $\hat{t}=5.34 .^{50}$ In iteration $i=1$ only the 797 movies which are screened to critics $\left(c_{j}=0\right)$ are used. Using assumption 1 , the observed $q_{j}$ is substituted for the unobserved expectation $E_{m}\left(q_{j} \mid 0, X_{j}\right)$ for these movies. Then all the independent and dependent variables are measured and we can estimate the regression easily. ${ }^{51}$ In later iterations, expected quality values $\left(E_{m_{i}}^{q r e}\left(q_{j} \mid c_{j}, X_{j}\right), E_{m_{i}}^{c e}\left(q_{j} \mid c_{j}, X_{j}\right)\right.$, or $\left.E_{m_{i}}^{c h}\left[E_{k}\left(q_{j} \mid c_{j}, X_{j}\right) \mid \tau_{d}\right]\right)$ after iteration $i$ will have been computed, and a regression on the full sample can be run.

3. Since simply using $\hat{R}\left(X_{j}, E_{m}\left(q_{j} \mid c_{j}, X_{j}\right)\right)=N \hat{t}\left(1+\exp \left[\widehat{\lambda_{m} \alpha} E_{m}\left(q_{j} \mid c_{j}, X_{j}\right)+\widehat{\lambda_{m} \beta} X_{j}+\widehat{\lambda_{m}} \hat{t}\right]\right)$ to estimate $R\left(X_{j}, E_{m}\left(q_{j} \mid c_{j}, X_{j}\right)\right.$ would produce biased estimates, non-parametric kernel regression techniques are used. A consistent Gaussian kernel regression is used to estimate

\footnotetext{
${ }^{50}$ Results are highly similar for $N=100 \times 10^{6}, 200 \times 10^{6}$, and $\hat{t}=5.34$.

${ }^{51} \mathrm{~A}$ crucial maintained assumption below is that the coefficient on expected quality, $\alpha$, in determining moviegoer attendance, and hence revenue, is the same for known-quality (screened) and unknown-quality (cold opened) movies.
} 
revenue from the parameter estimates from equation 15.

$$
\begin{aligned}
\hat{R}\left(X_{j}, E_{m}\left(q_{j} \mid c_{j}, X_{j}\right)\right) & =\hat{m}\left(-\lambda_{m}\left(\alpha E_{m}\left(q_{j} \mid c_{j}, X_{j}\right)+\beta X_{j}-\hat{t}\right)\right) \\
& =\frac{\sum_{l \in J_{i}} K_{h}(g(j)-g(l)) y_{l}}{\sum_{l \in J_{i}} K_{h}(g(j)-g(l))}
\end{aligned}
$$

where $g(j)=-\widehat{\lambda_{m}}\left(\hat{\alpha} E_{m}\left(q_{j} \mid c_{j}, X_{j}\right)+\hat{\beta} X_{j}-\hat{t}\right)$, and $K$ is the Gaussian kernel, $K_{h}(x)=$ $h \frac{1}{\sqrt{2 \pi}} e^{\frac{x}{2 h}}$, with bandwidth, $h=0.9 w\left\|J_{i}\right\|^{-1 / 5}$ where $w=\min \left(s_{y}, I Q R_{y} / 1.34\right)$ (from Silverman, 1986) and $J_{i}$ is the current iteration's set of movies (with length 797 for iteration 1, 856 thereafter).

4. The regression results from step 2 give iteration- $i$ coefficients $\hat{\alpha}_{i}$ and $\hat{\beta}_{i}$ and a response sensitivity $\hat{\lambda}_{m, i}$. Step 3 gives estimated revenue equation $\hat{R}_{i}$ from these parameters for different values of $X_{j}$ and $q_{j}$. From equation (3) we have

$$
\begin{aligned}
& E_{m}^{q r e}\left(q_{j} \mid X_{j}, 1\right)=\frac{\sum_{q=0}^{100} q \pi\left(X_{j}, q\right) P(q)}{\sum_{q=0}^{100} \pi\left(X_{j}, q\right) P(q)} \\
& \Rightarrow E_{m}^{q r e}\left(q_{j} \mid X_{j}, 1\right) \sum_{q=0}^{100} \pi\left(X_{j}, q\right) P(q)=\sum_{q=0}^{100} q \pi\left(X_{j}, q\right) P(q) \\
& \Rightarrow \sum_{q=0}^{100} \pi\left(X_{j}, q\right) P(q)\left[E_{m}^{q r e}\left(q_{j} \mid X_{j}, 1\right)-q\right]=0 \\
& \Rightarrow \frac{\sum_{q=0}^{100} P(q)\left[E_{m}^{q r e}\left(q_{j} \mid X_{j}, 1\right)-q\right]}{1+\exp \left(\lambda_{d}\left(\hat{R}\left(X_{j}, E_{m}^{q r e}\left(q_{j} \mid X_{j}, 1\right)\right)-\hat{R}\left(X_{j}, q_{j}\right)\right)\right)}=0
\end{aligned}
$$

where the last step follows from the definition of $\pi\left(X_{j}, q\right)$ (assumption 3). All the terms in 17 can be estimated from regression coefficients $\left(\hat{\alpha}_{i}, \hat{\beta}_{i}, \hat{\lambda}_{m, i}\right.$ from step 2$)$, determined from the revenue equation $\hat{R}_{i}$ (from step 3), fit from the quality distribution $P(q)$, or fixed by assumption $(\hat{t}, \mathrm{~N})$, except for $\lambda_{d}$ and $E_{m_{i}}^{q r e}\left(q_{j} \mid X_{j}, 1\right)$. To create an iteration of estimates of $E_{m}^{q r e}\left(q_{j} \mid X_{j}, 1\right) \forall j$ we fix a value of $\lambda_{d}$ and solve 17 for each movie $j$. Next, using fixed $\lambda_{d}$, 
and newly calculated estimates of $E_{m_{i}}^{q r e}\left(q_{j} \mid X_{j}, 1\right)$ for each movie, along with the estimated parameters in step 2 and revenue equations in step 3, the predicted iteration- $i$ probability $\left(\hat{\pi}_{i}\left(X_{j}, q_{j}, \lambda_{d}\right)\right)$ that each movie $j$ will be cold opened can be computed from assumption 3 .

Additionally, in the cursed procedure: For any fixed $\chi_{d}$, the newly calculated estimates of $E_{m}^{q r e}\left(q_{j} \mid X_{j}, 1\right)$ (see above equation 17) for each movie can be converted to $E_{m}^{c e}\left(q_{j} \mid X_{j}, 1\right)$, by equation 3. With those values, along with the estimated parameters in step 2 and revenue equations in step 3 , the predicted iteration- $i$ probability $\left(\hat{\pi}_{i}\left(X_{j}, q_{j}, \lambda_{d}\right)\right.$ that each movie $j$ will be cold opened can be computed from assumption 3 for each value of $\chi_{d}$.

The CH procedure obtains the probabilities that each movie is cold opened differently:

For a given $\lambda_{d}$ and $\tau_{d}$, we use our estimated values $\hat{\alpha}_{i}, \hat{\beta}_{i}, \hat{\lambda}_{m, i}$, and estimated revenue equation $\hat{R}_{i}$ to estimate $\pi_{k i}\left(q_{j}, X_{j}\right), E_{k i}\left(q \mid X_{j}, 1\right)$, and $\hat{R}_{i}\left(E_{k}\left(q \mid X_{j}, 1\right)\right)$ for $k=0 \ldots \bar{k}$ using equations $9-12 .{ }^{52}$ Since the probability of a given distributor being level $\mathrm{k}$ is $P\left(x=\left.n\right|_{d}\right)=$ $\tau_{d}^{n} e^{-\tau} / n$ ! and the probability of that distributor cold opening given he is level $\mathrm{k}$ is $\pi_{k}\left(q_{j}, X_{j}\right)$, the total probability that a movie is cold opened is

$$
\hat{\pi}_{i}\left(X_{j}, q_{j}, \lambda_{d}, \tau_{d}\right)=\sum_{k=0}^{\bar{k}} \pi_{k}\left(q_{j}, X_{j}\right) \times \tau_{d}^{n} e^{-\tau} / n !
$$

5. Step 4 is performed repeatedly for a grid search over sets of values of $\lambda_{d} \in A_{i}$ (or $\left(\lambda_{d}, \chi_{d}\right) \in$ $\left.\left\{A_{i}, B\right\},\left(\lambda_{d}, \tau_{d}\right) \in\left\{A_{i}, B_{i}\right\}\right)$, where the grid search becomes progressively finer across

\footnotetext{
${ }^{52}$ We used $\bar{k}=40$, because given regular $\tau$ values the probability of $k>40$ is nearly zero.
} 
iterations $i .53$

The maximum likelihood estimate $\omega\left(\lambda_{d, i}^{*},\left(\lambda_{d}^{*}, \chi_{d}^{*}\right)\right.$, or $\left.\left(\lambda_{d}^{*}, \tau_{d}\right)\right)$ is chosen from the set $\Omega_{i}$ $\left(A_{i},\left\{A_{i}, B\right\}\right.$, or $\left.\left\{A_{i}, B_{i}\right\}\right){ }^{54}$ That value satisfies

$$
\begin{aligned}
\omega_{i}^{*} & =\underset{\omega \in \Omega_{i}}{\operatorname{argmax}} L(\omega) \\
& =\underset{\omega_{i} \in \Omega_{i}}{\operatorname{argmax}} \prod_{j}\left[\hat{\pi}_{i}\left(X_{j}, q_{j}, \omega\right) c_{j} \times\left(1-\hat{\pi}_{i}\left(X_{j}, q_{j}, \omega\right)\right)\left(1-c_{j}\right)\right]
\end{aligned}
$$

where $L(\omega)$ is the joint probability that distributors would choose to screen and cold open each of the 856 movies in the exact manner they did under the QRE (or cursed, $\mathrm{CH}$ ) model with parameter(s) $\omega^{55}$

6. The value for the maximum likelihood parameter $\lambda_{d, i}^{*}$ determined from the last step 6 is then

\footnotetext{
${ }^{53}$ The initial $\lambda_{d, i}$ grid is $A_{1}=\{1,1.25, \ldots, 2\}$. The second grid $A_{2}$ takes an interval of values in increments of .1 around the maximum likelihood estimate $\lambda_{d, 1}^{*}$. The next grids $A_{i}$ take on values of values of width $.05,0.01,0.005$, and 0.001 around the maximum likelihood estimate $\lambda_{d, i-1}^{*}$.

For cursed: The initial $\lambda_{d, i}$ grid is $A_{1}=\{1,1.25, \ldots 2\}$. The second grid $A_{2}$ takes an interval of values in increments of .1 around the maximum likelihood estimate $\lambda_{d, 1}^{*}$. The next grids $A_{i}$ take on values of values of width $.05,0.01$, 0.005 and 0.001 , around the maximum likelihood estimate $\lambda_{d, i-1}^{*}$. The grid for $\chi_{d}, \mathrm{~B}$ is always $\{0,0.005, \ldots 1\}$.

For $C H$ : The initial $\lambda_{d, i}$ grid is $A_{1}=\{1,2, \ldots, 10\}$ and $\tau_{d, i}$ grid is $B_{1}=\{0.05,0.1, \ldots, 10\}$. The second grid $A_{2}$ takes an interval of values in increments of .1 around the maximum likelihood estimate $\lambda_{d, 1}^{*}$. The next grids $A_{i}$ take on values of values of width $.05,0.01,0.005$ and 0.001 , around the maximum likelihood estimate $\lambda_{d, i-1}^{*}$. For grids $i \geq 2, B_{i}=8.001, \ldots 9$.

${ }^{54}$ In the early steps of iteration (i.e., steps $1-3$ ) this value is determined by interpolating inside the grid to achieve more decimal precision.

${ }^{55}$ This process takes roughly 15 minutes (8 minutes for $\mathrm{CH}$ ) for each $\lambda_{d}$ on a single PC running Mathematica 5.2.
} 
used in equation 17 to solve for iteration- $i$ values of $E_{m_{i}}^{q r e}\left(q_{j} \mid c_{j}, X_{j}\right)$ for each of the 59 cold opened movies.

For the CH procedure: The maximum likelihood value $\lambda_{d, i}^{*}$ is used to compute the populationaveraged expectation for each of the 59 cold opened movies in the sample with

$$
E\left[E_{k}\left(q \mid X_{j}, 1\right) \mid \tau_{m}\right]=\sum_{k=0}^{\bar{m}} \pi_{k}\left(q_{j}, X_{j}\right) E_{k}\left(q \mid X_{j}, 1\right)
$$

The value of $\tau_{m}$ that minimizes the squared residuals in equation 6 is considered the best estimator for this step, that is

$$
\tau_{m, i}^{*}=\underset{\tau_{m}}{\operatorname{argmin}} \sum_{j: c_{j}=1}\left(\hat{R}_{i}\left(X_{j}, E\left[\left(E_{k}\left(q \mid X_{j}, 1\right) \mid \tau_{m}\right]\right)-y_{j}\right)^{2}\right.
$$

where $\hat{R}_{i}(\ldots)$ is estimated from the kernel estimation 15 in step 2 .

Now we have a full set of quality measures $q_{j}$ and expected qualities for every movie.

7. The process is stopped when the regression values and parameter estimates $\left(\lambda_{m}^{*}, \omega_{m}^{*}\right)$ from the current iteration $i$ are all within .001 of those from iteration $i-1$. Otherwise, the process is repeated with the iteration counter increased by one, starting with the regression step 2 . For the cursed procedure: When the process converges, a new value $\chi_{m}$ is calculated to minimize the sum of squares between predicted and actual values over all cold openings. That value is determined by

$$
\chi_{m}^{*}=\underset{\chi_{m}}{\operatorname{argmin}} \sum_{j: c_{j}=1}\left(\hat{R}\left(X_{j},\left(1-\chi_{m}\right) E_{m}^{r e *}\left(q \mid X_{j}, 1\right)+\chi_{m} \bar{q}\right)-y_{j}\right)^{2}
$$


where $\hat{R}(\ldots)$ is the last estimate done in step 3 .

8. The process is repeated 100 more times with different bootstrapped data sets. A bootstrapped data set is created by randomly sampling with replacement from the 856 movies in the original data set. Parameter estimates are obtained by repeating steps $1-7$. Standard errors (see Table 8) are calculated by taking the standard deviation of these 100 parameter estimates. ${ }^{56}$

${ }^{56}$ Depending on the bootstrap and number of iterations, the process for a single bootstrap takes $2-6$ hours for QRE (2-6 for cursed, 2-12 for $\mathrm{CH}$ ) on a single PC running Mathematica 5.2 